\title{
Mammalian Kidney Development: Principles, Progress, and Projections
}

\author{
Melissa H. Little ${ }^{1}$ and Andrew P. McMahon ${ }^{2}$ \\ ${ }^{1}$ Institute for Molecular Bioscience, The University of Queensland, St. Lucia, Brisbane 4072, Australia \\ ${ }^{2}$ Department of Stem Cell and Regenerative Biology, Department of Molecular and Cellular Biology, Harvard Stem Cell \\ Institute, Harvard University, Cambridge, Massachusetts 02138 \\ Correspondence: M.Little@imb.uq.edu.au
}

\section{SUMMARY}

The mammalian kidney is a vital organ with considerable cellular complexity and functional diversity. Kidney development is notable for requiring distinct but coincident tubulogenic processes involving reciprocal inductive signals between mesenchymal and epithelial progenitor compartments. Key molecular pathways mediating these interactions have been identified. Further, advances in the analysis of gene expression and gene activity, coupled with a detailed knowledge of cell origins, are enhancing our understanding of kidney morphogenesis and unraveling the normal processes of postnatal repair and identifying disease-causing mechanisms. This article focuses on recent insights into central regulatory processes governing organ assembly and renal disease, and predicts future directions for the field.

\section{Outline}

1 An overview of cell players and cellular processes in metanephric kidney development

2 Regulating ureteric bud outgrowth and branching

3 The fate of the multipotent metanephric mesenchyme

4 Nephron induction via a mesenchyme-toepithelial transition
5 Patterning, segmentation, and specialization of the epithelial networks

6 Postnatal events in functional renal maturation

7 Reassessing renal disease, repair, and regeneration using developmental biology

8 Looking to the future

References

Editors: Patrick P.L. Tam, W. James Nelson, and Janet Rossant

Additional Perspectives on Mammalian Development available at www.cshperspectives.org

Copyright (C 2012 Cold Spring Harbor Laboratory Press; all rights reserved; doi: 10.1101/cshperspect.a008300

Cite this article as Cold Spring Harb Perspect Biol 2012;4:a008300 


\section{AN OVERVIEW OF CELL PLAYERS AND CELLULAR PROCESSES IN METANEPHRIC KIDNEY DEVELOPMENT}

The kidney eliminates nitrogenous waste, maintains the volume, composition, and pressure of the blood, and the density of our bones. The workhorse of this complex machine is the nephron: a human kidney comprises 200,000 to 1.8 million of these intricately patterned and functionally compartmentalized epithelial structures assembled over a lengthy period of fetal life (Hughson et al. 2003). The permanent, or metanephric, kidney of the postnatal mammal is actually the last of three excretory organs to form from the intermediate mesoderm (IM) by mid-gestation: pronephric, mesonephric, and metanephric kidneys appear in a cranial to caudal sequence. This article focuses on the metanephric kidney.
Cell-fate studies tracing descendants of intermediate and dorsal lateral plate mesoderm cells expressing the transcriptional regulator Osr 1 identify Osr ${ }^{+}{ }^{+}$cells as founders of the principle cellular components of the metanephric kidney: the main body of the nephron, vascular and interstitial cell types, and the nephric duct (Fig. 1) (Mugford et al. 2008a).

Interactions amongst the different $\mathrm{Osrl}^{+}$derivatives are critical for kidney development: mouse organ culture experiments in the 1950-1970s established the general framework (Saxen 1987). The nephric duct, a Pax ${ }^{+} \mathrm{Lhxl}^{+}$ $\mathrm{Gata}^{+}$epithelial derivative of a portion of the $\mathrm{Osr}^{+}{ }^{+} \mathrm{IM}$ extends in a rostral to caudal direction from E9.5. A bud, the ureteric bud (UB), grows out from the nephric duct at the hind-limb level around E10.5-11.0 of mouse development. Subsequent branching and growth of the ureteric epithelium generates the arborized network of the collecting duct system transporting urine from the nephron to the

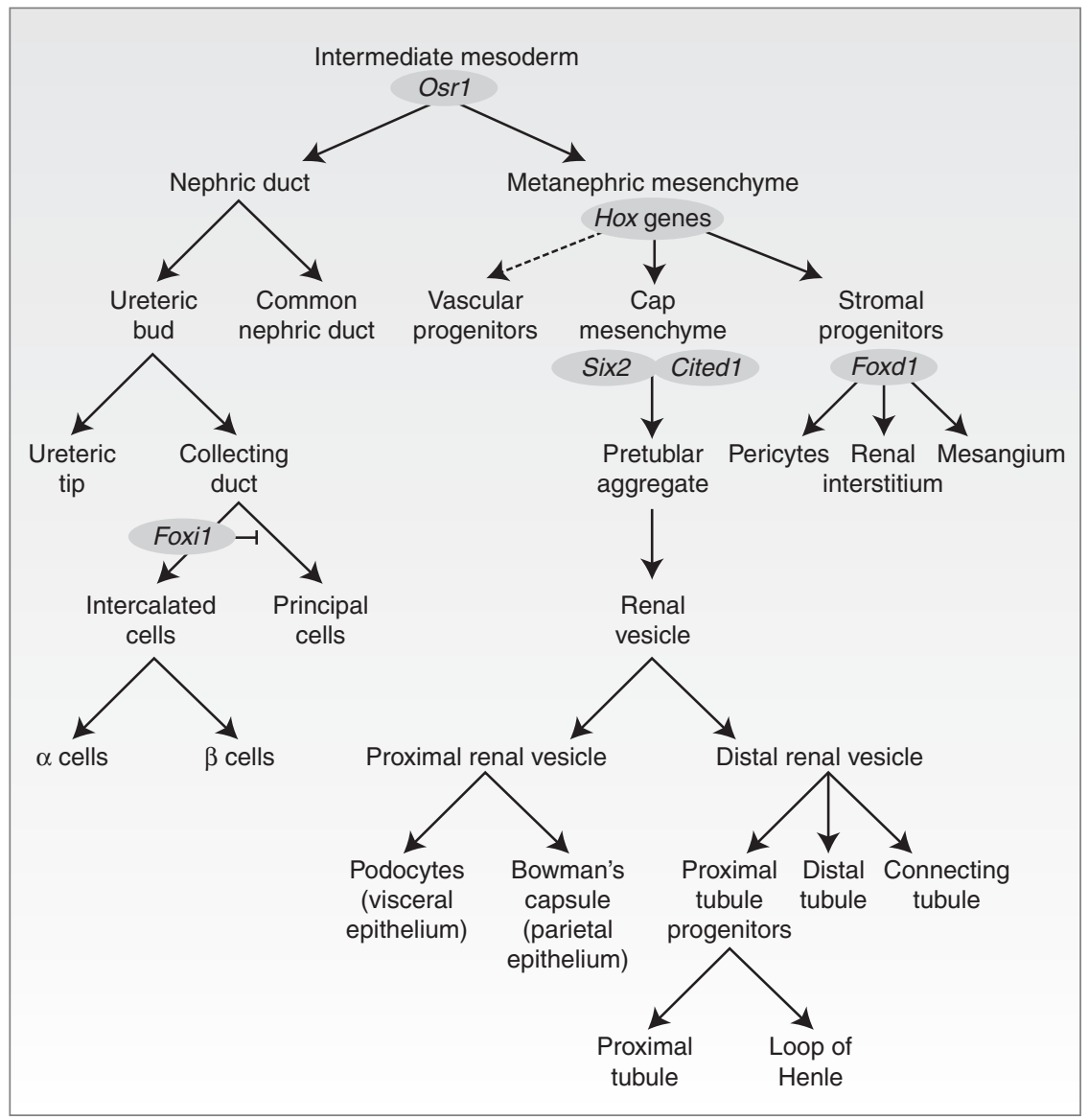

Figure 1. Lineage relationships within the developing mammalian metanephros. The metanephros arises from the intermediate mesoderm, which gives rise to the nephric duct and the metanephric mesenchyme. The former gives rise to the cells of the collecting duct system, whereas the latter gives rise both to the epithelial components of the nephrons (excluding collecting duct) as well as stromal and vascular elements. Key marker genes for compartments are indicated in gray ovals. 
bladder via the ureter. The initial outgrowth, and subsequent branching, of the ureteric epithelium is directed by signals from metanephric mesenchyme (MM) surrounding the branching ureteric tips. Molecular and cell-fate studies have identified three key progenitor populations within this mesenchyme (Fig. 1). Six $2^{+}$Cited $1^{+}$MM cells closest to the branching tips undergo an epithelial transformation establishing the renal vesicle (RV) in response to ureteric signals. The RV is the precursor for all components of the main body of the nephron from podocytes (proximally) to the connecting segment plumbing into the ureteric epithelium (distally) (Boyle et al. 2008; Kobayashi et al. 2008). A second MM subcompartment of Foxd $1^{+}$ cells generates interstitial cell types, including pericytes and their specialized glomerular counterpart, the mesangial cells (Hatini et al. 1996; Humphreys 2010). Finally, $\mathrm{Flk1}^{+}(\mathrm{Kdr} /$ Vegfr2) vascular progenitors exist within the MM (Gao et al. 2005; Mugford et al. 2008a), and may actively populate newly forming vasculature through a vasculogenic process, and potentially support UB outgrowth (Gao et al. 2005). Angiogenic ingrowth of blood vessels likely provides an additional mechanism for vascularizing the kidney (Abrahamson and Robert 2003).

\subsection{Specification of the Metanephric Anlagen}

The establishment of the nephric duct requires the cellautonomous activity of either Pax 2 or Pax8, closely related PAX-family transcriptional regulators (Bouchard et al. 2002), whereas the LIM family member, Lhx1, is essential for caudal extension and development of the duct (Tsang et al. 2000; Pedersen et al. 2005). Consequently no UB forms in these mouse mutants. At a later stage, Pax2 and Gata3 (a transcriptional regulator that appears to act downstream from PAX and LIM factors) are required to establish the UB (Torres et al. 1995; Lim et al., 2000; Grote et al. 2006).

With respect to the MM, key transcription factors, including Osr1, Wt1, Hoxa11, Hoxc11, Hoxd11, Sall1, Six1, and Eya1, are essential for normal specification. Wt1 acts broadly and early within the IM, at least in part as an antiapoptotic factor to support MM development (Kriedberg et al. 1993). In contrast, Osr 1 and the Hox 11 paralog members appear to have a more direct role in specifying cell fates as no MM forms in their absence, resulting in renal agenesis (Wellick et al. 2002; James et al. 2006; Mugford et al. 2008a). Chick studies indicate that Osr1 blocks the formation of endoderm, and it is the secondary encroachment of endodermal signals that inhibits mesonephric and metanephric kidney development (Mudumana et al. 2008), whereas Hox11 paralogs play a more direct role in distinguishing a metanephric program (Wellik et al. 2002;
Mugford et al. 2008b). A temporal restriction in the fate of the $\mathrm{Osrl}^{+}$population ensures that at the initiation of nephrogenesis, E11.5 in the mouse, $\mathrm{Osr}^{+}$cells are largely confined to the nephron progenitor population (Mugford et al. 2008a). Sall1, Six1, and Eyal are essential for specific aspects of metanephric function, notably, the initial cell interactions that lead to UB outgrowth (Sato et al. 2003; Xu et al. 2003; Sajithlal et al. 2005). Importantly, the expression of many of these genes within specific compartments of the kidney at later stages suggests continuing roles that have not been thoroughly investigated. Further, the analysis of potential regulatory actions of certain factors within the $\mathrm{MM}$ is complicated by expression in multiple kidney compartments; for example, Pax2 acts in the UB but expression is also present in the MM, however a MM-specific function for Pax2 has not been addressed.

These key transcriptional regulators are presumed to regulate MM specification by sequence-specific binding of DNA targets, although interactions amongst these factors are likely to influence target specificity (Little et al. 1999). In the MM, Eya/Hox/Pax (Gong et al. 2007) and Eya/Six/Pax (Brodbeck and Englert 2004) protein complexes have been described, suggesting coordinated specification resulting from coexpression of these proteins. Several additional layers of complexity have arisen that complicate this further. Wt1 has been shown to directly bind RNA (Caricasole et al. 1996), to interact with the transcriptional machinery (Larsson et al. 1995) and shuttles between the nucleus and the cytoplasm (Vajjhala et al. 2003), suggesting potential roles in direct regulation of transcription and translation. The stage-dependent association of Pax2 with trithorax and polycomb complex proteins indicates that Pax 2 may regulate activation or silencing of loci through histone methylation (Cai et al. 2003; Patel et al. 2007).

The power of the mouse as a model of renal disease is exemplified by the analysis of congenital defects in human kidney development. Collectively termed congenital anomalies of the kidney and urinary tract (CAKUT), CAKUT phenotypes are broadly classified and include hypoplasia, dysplasia, multicystic dysplasia, and most commonly vesicoureteric reflux (VUR) resulting in obstructive nephropathy (reviewed in Winyard and Chitty 2008; Song and Yosypiv 2011). Dominant renal hypodysplastic kidneys (RHD) without overt VUR or megaureter present in a number of syndromes, all of which show mutations in key regulators of early kidney specification first discovered in the mouse. These include mutations in PAX2 (renal-coloboma syndrome), EYA1 and SIX1 (branchio-oto-renal syndrome), and SALL1 (Townes-Brocks syndrome). Fifteen percent of patients with RHD show mutations in TCF2/HNF1B or PAX2, whereas EYA1, SALL1, and SIX1 mutations are less 
frequent. However, the resulting phenotypes are highly variable. CAKUT with VUR is more commonly associated with genes involved in UB outgrowth such as ROBO2/ SLIT2 and GDNF/RET (Hirschprung's disease) (Manie et al. 2001) as we discuss below.

\section{REGULATING URETERIC BUD OUTGROWTH AND BRANCHING}

\subsection{Gdnf/Ret Signaling}

The Gdnf/Ret pathway is a critical regulator of UB outgrowth and branching. Gdnf, secreted by the MM, activates a Gfral/Ret receptor-tyrosine kinase (RTK) complex initiating a signaling cascade that up-regulates expression of the Ret receptor and triggers outgrowth of Ret positive cells from the nephric duct toward the GDNF signal (Fig. 2) (reviewed in Costantini and Kopan 2010). Loss of Gdnf, Ret, or Gfral in the mouse leads to an almost completely pen-

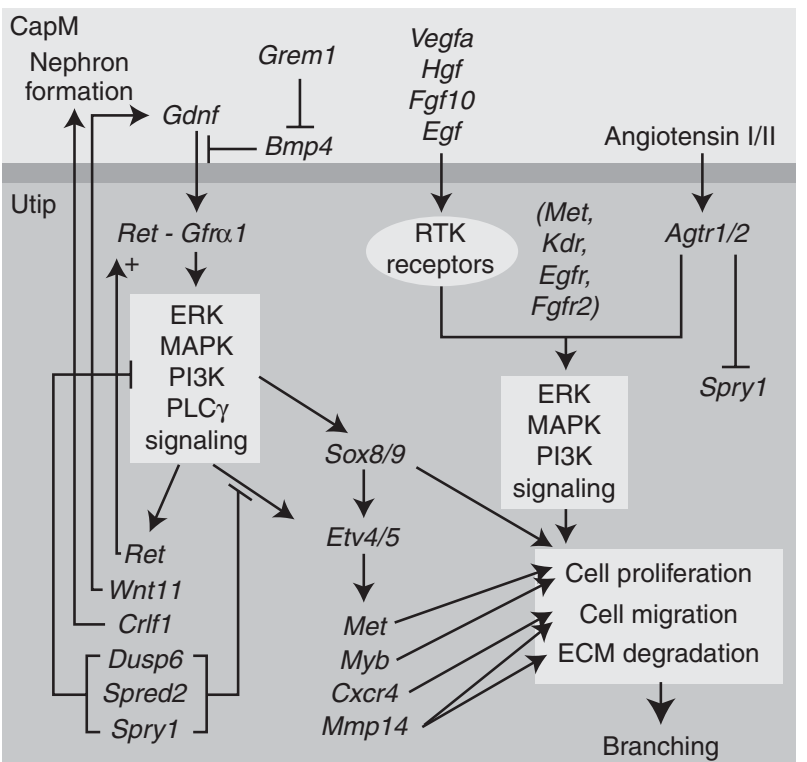

Figure 2. An overview of the major signaling pathways involved in ureteric epithelial branching. The diagram represents an epithelial cell at the tip of the ureteric epithelium (Utip) and an adjacent cap mesenchyme (CapM) cell. Growth factors (glial-derived neurotrophic factor [Gdnf], vascular endothelial growth factors [Vegfa], hepatocyte growth factor [Hgf], fibroblast growth factor 10 [Fgf10], epidermal growth factor [Egf], angiotensin I/II, formed via rennin cleavage of angiotensinogen $[\mathrm{Agt}]$ ) from the adjacent cells bind to a variety of receptor-tyrosine kinases (Ret/Gfro1, Kdr, Met, Fgfr2, Egfr, and Agtr1/2, respectively) on the surface of the Utip cell triggering signaling cascades that regulate cell proliferation, migration, and extracellular matrix (ECM) degradation. The combined actions of these signaling pathways is continued branching and elongation of the ureteric epithelium to form the collecting duct system. Target genes known to be induced via such signaling are indicated. etrant failure of UB outgrowth, and resulting kidney agenesis (Jain et al. 2009). Patients with Hirschsprung's disease present with agangliosis of the intestine as a result of mutations in either Gdnf or Ret; the intestinal pathology is coupled with renal agenesis, hypoplasia, or dysplasia (Pini Prato et al. 2009). Whereas a total loss of Ret in the mouse results in kidney agenesis, inactivating mutations (such as Y1062F) that remove a specific site of intracellular phosphorylation of the Ret receptor results in renal hypoplasia (Wong et al. 2005; Jain et al. 2006, 2010). This highlights the ongoing role for Gdnf/Ret pathway action beyond the initial outgrowth of the UB. Interestingly, mutation of a different tyrosine, Y1015F, leads to megaureter, and duplex or supernumerary ureters, multiplexed kidneys, or pelvic dilatation; phenotypes more suggestive of excessive branching and hyperactivity of a Ret-triggered pathway (Jain et al. 2010). Phosphorylation of Y1015 triggers PLCy signaling, whereas Y1062 phosphorylation triggers $\mathrm{PI} 3 \mathrm{~K}$ and mitogen-activated protein kinase (MAPK) signaling. Hence, an appropriate balance in distinct RET outputs is essential for normal development of the ureteric network. Murine genetics will continue to illuminate the intricacies of this complex regulatory process.

\subsection{A Role for Other Initiators of RTK Signaling and Modifiers of the Signal}

Ret is not the sole RTK mediating branching (see Fig. 2); studies with Fgf and Fgfr mutants indicate a role for FGF signaling (reviewed in Bates 2011). In the appropriate genetic background, Fgf10 can compensate, at least partially, for the loss of Gdnf (Michos et al. 2010). Vegfa is also reported to increase UB branching in a dose-sensitive fashion, whereas inactivating antibodies inhibit branching (Tufro et al. 2007; Marlier et al. 2009). Vegfa effects may be mediated through Flk1 (Kdr/Vegfr2) receptor binding or the direct interaction of Vegfa with Ret (Tufro et al. 2007). Hgf binds to the RTK receptor, Met, and the addition of exogenous Hgf has long been reported to affect branching in culture. Selective deletion of Met in the ureteric epithelium results in reduced branching, and branching can be restored by another RTK receptor ligand, Egf (Ishibe et al. 2009). Further, Angiotensin I/II binding to Agtr1/ Agtr2 in the ureteric tips evokes tyrosine phosphorylation of Egfr, stimulating branching (Yosypiv et al. 2006) and upregulating Ret tyrosine phosphorylation (Song et al. 2010).

Feedback inhibition by the RTK signaling inhibitor Sprouty 1 (Spryl) restricts the site of branch initiation; multiple buds emerge from the nephric duct of Spry1 mouse mutants (Basson et al. 2006). Gdnf expression is also restricted along the anterior-posterior axis of the mouse embryo by the actions of Foxc2, Slit2/Robo2, and 
Bmp4 signaling (Kume et al. 2000; Miyazaki et al. 2003; Grieshammer et al. 2004). Gremlin (Grem1), a secreted Bmp4 antagonist, fine tunes bone morphogenetic protein (BMP) input enabling branching (Michos et al. 2007). Once again, the parallels between mouse and human are evident in CAKUT where mutations in BMP4, FOXC2, and $\mathrm{ROBO} 2$ have been documented (Nakano et al. 2003; Tabatabaeifar et al. 2009). Together, these inhibitory inputs ensure the outgrowth of a single UB from the nephric duct, at an appropriate time and axial position, whereas their loss leads to duplicated ureters, multiplexed kidneys, and commonly, VUR.

Recent advances have led to an increasing appreciation of the mechanisms of RTK signaling, including downstream targets and the role of different arms of the Retdriven signaling cascade (Fig. 2). Potential targets of Ret signaling have been elucidated via microarray comparisons of isolated UBs cultured with or without $\mathrm{Gdnf}$ ( $\mathrm{Lu}$ et al. 2009). These include the transcriptional regulatory factors, Etv4 and Etv5, general targets of Gdnf and Fgf signaling in diverse tissue contexts. In the kidney, Etv4 and Etv5 show Gdnf- and Fgf-dependent regulation in the branch tips, and branching is severely compromised when their combined activity is lowered in compound mutant embryos. Although the data indicate that Etv4/5 establish a transcriptional output critical for branching growth, their targets remain to be determined ( $\mathrm{Lu}$ et al. 2009). Sox8 and Sox 9 may act downstream from Ret signaling to activate effector genes such as Spry1 and Etv5, as well as acting independently to control tip identity. Hence, removal of Sox9 activity results in a premature cessation of branching, thereby terminating nephrogenesis (Reginensi et al. 2011).

RTK-mediated signaling is not the only regulatory pathway controlling ureteric tree morphogenesis. Wnt signaling within the ureteric epithelium is also important. Normal branching, maintenance of a tip progenitor transcriptional signature, and suppression of late markers of ureteric differentiation depend on $\beta$-catenin (Ctnnb1) activity in the ureteric epithelium (Marose et al 2008; Bridgewater and Rosenblum 2009; Karner et al. 2011). In addition, chimeric studies show selection against cells rendered nonresponsive to specific Wnt ligand inputs through mutation of surface Wnt receptors, Frizzled homologs 4 and 8 (Fzd4/Fzd8) (Ye et al. 2011).

\subsection{Branching at the Cellular Level}

Ret activity regulates the migration and arrangement of cells within the epithelial UB. New tools for live imaging, coupled with mouse models highlighting the shape and outline of individual cells, are assisting in our understanding of this dynamic process (Chi et al. 2009a). The recent double knockout of the actin depolymerizing factors cofilin1 (Cfl1) and destrin (Dstn) reveal a critical role for the actin cytoskeleton in morphogenesis of the ureteric tree (Kuure et al. 2010). Interestingly, Ret activity is also critical for cells to maintain their position within the branching tip, and consequently, to maintain a branching capability (Chi et al. 2009a). Ret mutant cells rapidly sort to nonbranching stalk regions where they can grow quite normally. The logic for this competitive interaction is evident, although the mechanism is unclear. Ret expression in the tip is reinforced by a feedback circuit wherein Wnt11, produced at the tips under Gdnf/Ret control, acts on the cap mesenchyme to maintain normal GDNF levels and branching activity (Pepicelli et al. 1997). Wnt11 activity is enabled by Gremlin-mediated restriction of BMP signaling (Michos et al. 2007). In addition, retinoic acid, produced by interstitial mesenchyme progenitors, contributes to the regulation of Ret expression within branch tips (Rosselot et al. 2010). The imaging of chimeric animals in which only a portion of the ureteric epithelium retains normal Ret function clearly shows active and ongoing cellular migration and shape changes within the branching epithelium (Chi et al. 2009b). Branching continues for days or weeks, depending on the mammalian species; the continued activity of these same pathways suggests a continuing regulatory role. However, the later branching phenotypes observed in mice defective in Semaphorin-directed signaling (Sema3a/Nrpl and Sema4d/Plxnb1) suggest that there are additional regulatory inputs modifying the branching process, and compensatory mechanisms buffering against branching defects (Turfo et al. 2008; Perälä et al. 2011).

In summary, several signaling pathways regulate the branching process. Each of these is predicted to trigger multiple intracellular pathways, some of which regulate a branching tip transcriptional program, whereas others modify cellular properties such as cell shape, movement, and division. Much remains to be learned about the interplay and integration of these pathways. For this, reliable ex vivo models are needed to visualize, quantify, and experimentally manipulate branching growth. The growth of standard kidney explant cultures is horizontally exaggerated across the surface of the filter on which these organoids develop. Hence, explant culture does not recapitulate normal patterning. Lung branching displays a stereotypical organization (Metzger et al. 2008), whereas kidney branching has been assumed to represent a "simple" radial dichotomous branching routine. However, the resulting organ is not spherical. Indeed, a distinct caudal to rostral bias in branching is seen from the first branching event (Raatikainen-Ahokas et al. 2000). The development and application of 3D culture models and 3D imaging systems that include real time imaging capability will enable an accurate 
assessment of the "rules" underpinning arborization of the collecting duct network.

\section{THE FATE OF THE MULTIPOTENT METANEPHRIC MESENCHYME}

Surrounding the invading UB, and driving its branching via the secretion of Gdnf, is the MM. As outlined earlier, the $\mathrm{MM}$ is a complex population of progenitor types that contribute to the elaboration of distinct components of the kidney.

\subsection{Cap Mesenchyme-The Nephron Progenitor Population}

The cells closest to the ureteric tips condense to form a discrete subdomain of the MM: the committed mesenchyme, capping mesenchyme, or cap mesenchyme (CM). This region of densely packed and histologically distinct mesenchyme, associates with the tips of the ureteric epithelium, not the extending trunks. As the kidney grows, this mesenchyme and the adjacent branching tips are restricted to the periphery of the developing kidney, the nephrogenic zone (Fig. 3). The development of promoter-specific Cre mice

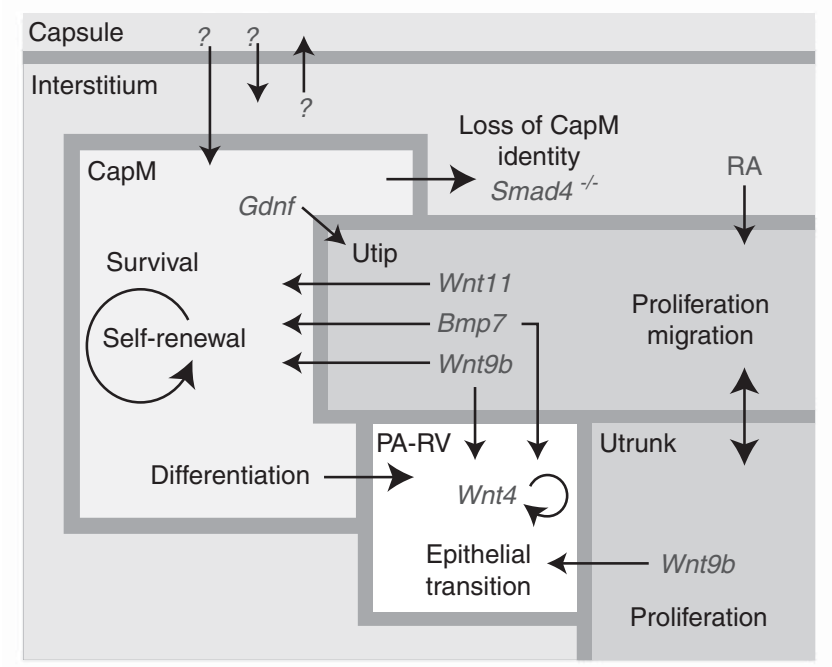

Figure 3. A model of the nephrogenic niche. The key cellular compartments within the nephrogenic niche at the periphery of the developing kidney include the ureteric tip (Utip), cap mesenchyme (CapM), ureteric trunk (Utrunk), capsule, interstitium, and the forming nephrons (pretubular aggregates-renal vesicles [PA-RV]). Each compartment has a characteristic spatial arrangement in the embryonic kidney. Indicated within each compartment are the cellular activities occurring. Loss of CapM identity occurs when Smad4 is selectively removed from CapM (Bmp7Cre) (Oxburgh et al. 2004). Large arrows indicate the presence of signals between compartments to control development. Key marker genes for the compartments are indicated in gray text with small arrows indicating the compartment being influenced. has shown that $\mathrm{Six} 2^{+} \mathrm{Cited} 1^{+} \mathrm{CM}$ cells comprise a nephron-committed, multipotent, self-renewing progenitor population responsible for generating all segments of the nephron from podocyte to connecting segment (Fig. 1) (Boyle et al. 2008; Kobayashi et al. 2008). The specification of this population is likely independent of the nephric duct as it occurs before UB ingrowth, potentially reflecting the segregation of Six $2^{+}$and Foxd $1^{+}$lineages from a postulated $\mathrm{Osrl}^{+}$common progenitor. Interestingly, whereas the loss of Cited1 has no kidney phenotype (Boyle et al. 2007), the removal of Six 2 activity results in the quantitative, premature mesenchyme-to-epithelial transition (MET) of all CM to RV on initial ingrowth of the UB; as a result, nephrogenesis ceases at an early stage (Self et al. 2006). Thus, Six2 is a critical regulator of the CM progenitor state. Not all Six $2^{+}$ cells are equivalent in their ability to propagate and selfrenew. Six2 expression overlaps with Wnt4 expression in pretubular aggregates, and cell-fate studies indicate that Wnt $4^{+}$cells have exited the nephron progenitor pool and committed to nephrogenesis (Kobayashi et al. 2008). In contrast, the Cited $1^{+}$component of the Six 2 population is nonoverlapping with Wnt4 and better defines the progenitor compartment (Mugford et al. 2008a). Interestingly, detailed expression mapping of a number of transcriptional regulators within the $\mathrm{CM}$ indicates additional subdomains within the Cited $1^{+} \mathrm{Six} 2^{+}$nephron progenitor pool, distinguished by Eyal and Meoxl (Mugford et al. 2008a). How these molecularly defined subcompartments relate to functional characteristics of the progenitor population has not been determined.

Currently, no culture system exists that can stably propagate nephron progenitors, although FGF and BMP family members are thought to play an important role. Fgf2 and Bmp7 enable survival of MM explants (Dudley et al. 1999). Consistent with a critical role for FGF signaling within the MM itself, conditional removal of Fgfr 1 and 2 from MM results in a failure of Six 2 expression, and agenesis of the kidneys (Poladia et al. 2006). Bmp7 displays a complex expression pattern that includes the $\mathrm{CM}$, and mutants lacking Bmp7 show an early arrest of development with enhanced cell death amongst CM nephron progenitors (Dudley et al. 1995). A biphasic role for Bmp7 has been proposed where Bmp7 elicits MAPK-dependent CM proliferation and regulates cell survival and interstitial progenitor phenotype via Smad signaling (Oxburgh et al. 2011). Nephrospheres, clonal, long-term self-renewing cell cultures, have been generated in media containing bFGF and thrombin. However, epithelial potential is lost in favor of a broad mesodermal potential (Lusis et al. 2010). Clearly, a better definition of the in vivo niche will aid in developing a supportive in vitro system. In vivo, $\mathrm{CM}$ receives signals from ureteric and interstitial elements, 
and potentially from the outermost cells of the renal capsule (Fig. 3). Although some cell interactions are mediated by diffusible signals, others may be contact mediated and more difficult to replicate in an in vitro setting.

\subsection{Stromal and Vascular Progenitors}

Molecular and cell-fate tracing studies have identified vascular and interstitial/stromal progenitors as the two other major cell populations present in the MM adjacent to the branching ureteric tips (Fig. 1). Much less is known about each of these elements of the kidney than their CM counterpart. Interstitial progenitors are identified by expression of the transcriptional repressor Foxd1; a number of other regulatory factors provide a molecular signature for this cell type (Humphreys et al. 2010; A Kobayashi and AP McMahon, unpubl.). As with the CM, the Foxd1 population comprises a self-renewing, multipotent, progenitor pool that is responsible for generating nonepithelial cell fates in the adult kidney, including pericytes and mesangial cell types, identified by their close association with nonglomerular and glomerular vasculature, respectively, and the expression of smooth muscle actin (Humphreys et al. 2010). Both populations are thought to play an important role in maintaining and modifying vasculature integrity and the accumulation of cells with a pericytelike phenotype is a hallmark of kidney fibrosis (Humphreys et al. 2010). In addition to these vascular-associated derivatives of Foxd1 cells, cell-fate analysis indicates that Ren $1^{+}$cells of the juxtaglomerular apparatus, a specialized sensory structure that monitors and regulates blood pressure through the production of Renin, express Foxd1 and may originate from the same interstitial progenitor pool (A Gomez pers. comm.; AP McMahon, JJ Guo, and JA McMahon, unpubl.). Finally, scattered interstitial cells with no clear vascular association, and no known function, are derived from Foxd $1^{+}$cells (Humphreys et al. 2010). The molecular and cellular processes that maintain the interstitial progenitor compartment and regulate commitment to distinct cell fates are unknown, but the stereotypical arrangement of the UB, CM, and interstitial progenitor pool suggest that local cell interactions within the nephrogenic niche are likely to be critical.

Experimental analysis of the origins of the vascular component of the kidney through recombination experiments distinguishing kidney explants from host cells has led to conflicting conclusions. One set of experiments shows that vasculature bears the genetic signature of the early MM explant consistent with vascular progenitors being an intrinsic component of the MM cocktail at the outset of kidney development (Hyink et al. 1996; Robert et al. 1998). Consistent with this view, nontubular Flk $1^{+}$ $(\mathrm{Kdr} /$ Vegfr2) vascular progenitors make up the bulk, if not all, of the Foxd ${ }^{-}$; Six $2^{-}$mesenchymal cell types clustered about the UB (Mugford et al. 2008a). In contrast, kidney grafting experiments point to ingrowth of vasculature components from the graft site, consistent with extrarenal assembly and ingrowth of the vascular tree (Takeda et al. 2006). The simplest view is that both mechanisms prevail. In one model, assembly of a complex functional unit like the glomerulus may require the orchestrated commitment and assembly of nephron, mesangial, and vascular components from local progenitor pools, whereas some of the larger vessels and medullary vasculature may originate through an independent ingrowth of blood vessels into the developing kidney. The absence of genetic tools distinguishing nontubular (early) and tubular (late) vascular components, or cortical and medullary vasculature, has hindered our understanding of the development of this critical component of the kidney. Further, although vascular progenitors are clearly localized within the MM/UB niche, we do not know whether this represents an active role of the niche environment or simply the invasion of vascular progenitors within a permissive environment.

\section{NEPHRON INDUCTION VIA A MESENCHYME-TO-EPITHELIAL TRANSITION}

\subsection{Primary Induction}

Early work by Grobstein, Saxen, and their colleagues showed that the route from $\mathrm{CM}$ to nephron required a permissive signal from the UB to the $\mathrm{CM}$ - a primary induction event. This signaling triggered MET within a CM subpopulation generating the RV. A number of factors have been linked to this process on the basis of in vitro studies of RV induction in different species (for review, see Carroll and McMahon 2003). In the mouse, canonical Wnt signaling directed by Wnt9b/ $\beta$-catenin (Ctnnb1) has emerged as the dominant pathway initiating this process. Wnt9b is present within the ureteric epithelium at the appropriate time and place, is essential for the earliest responses of RV-forming mesenchyme, and heterologous cells producing Wnt9b are sufficient to induce RV formation in isolated MM explants through a Wnt9b, cell contact-dependent process (Carroll et al. 2005). In addition, Wnt9b is essential for development of other IM-derived structures: the tubules of the mesonephric kidney and the Mullerian duct, the anlagen of the female reproductive tract (Carroll et al. 2005). Together these data indicate that Wnt9b activity is a key regulatory signal in the inductive process. Further, they lend support to the model that Wnt9b acts permissively, the response being determined by preprogrammed properties intrinsic to the specific IM derivative receiving the $\mathrm{Wnt} 9 \mathrm{~b}$ signal. 
Wnt signals act on their target cells to regulate cellular phenotype through transcriptional and nontranscriptional processes. At the transcriptional level, a canonical signaling pathway has been identified throughout metazoans in which the engagement of a Wnt ligand with a cell-surface Frizzled (Fzd) receptor results in the activation of a signal transduction pathway leading to elevated levels of cytoplasmic $\beta$-catenin (Ctnnb1). In the absence of $\beta$-catenin, Lef/ Tcf DNA-binding transcriptional factors bind targets and form repressor complexes silencing transcription. Direct complex formation between cytoplasmic $\beta$-catenin and Lef/Tcf proteins switches their mode of action to transcriptional activation (for review, see Angers and Moon 2009). $\beta$-catenin is essential for RV induction (Park et al. 2007). Further, the elevation of cytosolic $\beta$-catenin directly within $\mathrm{CM}$ progenitors through genetic means initiates RV induction in Wnt9b mutants (Park et al. 2007). Thus, there is strong evidence that a Wnt9b-directed canonical signal is the key initiating event in murine nephron formation.

The observation that Six2 is required to maintain CM, whereas Wnt9b commits a subset of this population to a $\mathrm{RV}$ fate, raises a number of interesting questions. Is there a common mechanistic target of these distinct regulatory actions? Why does only a subset of the Six ${ }^{+}$CM population initiate a RV program at each round of ureteric branching? How is nephrogenesis brought to an end at an appropriate time ensuring a normal complement of nephrons? Post nephrogenesis, what governs subsequent growth and size of the kidney? Compound mutants lacking both Six2 and Wnt9b function resemble Wnt9b mutants (Kobayashi et al. 2008). Consequently, premature ectopic RV formation in Six 2 mutants, like its normal counterpart, is Wnt9b dependent. This suggests a model in which Six2 acts to block Wnt9b signaling in some, but not all, of the nephron progenitors. Given that Six2 is a transcriptional regulator, Six2-mediated inhibition could reflect direct Six 2 action on transcriptional targets. To date, the only targets identified for Six 2 are Gdnf and Six 2 itself, an autoregulatory feed-forward process that is thought to promote its own expression (Brodbeck et al. 2004). In addition to their antagonistic activities, recent transcriptional profiling and genetic interaction studies suggest that a subset of genes within the CM are positively and cooperatively regulated by Six 2 and Wnt9b (Karner et al. 2011). What might govern the differential actions of these pathways and the regional specificity of the inductive response within the CM is unclear. One possibility is the differential action of other regulatory components in concert with Six 2 and Wnt9b; non-Wnt signals linked to RV induction are possible candidates. Alternatively, different levels of Wnt9b may have different regulatory actions. What is evident is that not all regions of the CM are likely be exposed to the same milieu of non-CM-derived signals, the levels and composition of factors are expected to vary, and regional differences may determine that RVs form in the "armpit" region of the nearest terminal UB branch (Fig. 3).

\subsection{From Committed CM to RV}

Following from a primary Wnt9b induction, subsequent signaling regulates epithelial formation, and activates downstream patterning genes central to the early steps of segmenting the nephron. Two key early Wnt9b-response genes, themselves secreted proteins, are critical for this process: Wnt4, another Wnt family member, and Fgf8, a member of the fibroblast growth factor family. Expression of both genes is detected in pretubular aggregates, closely adherent clusters of cells beneath the UB tips; each is essential for propagation of the inductive response and the formation of epithelial RVs. Their precise regulatory interactions, explored through genetic analysis, put Fgf8 upstream of Wnt4 (Grieshammer et al. 2005; Perantoni et al. 2005). Wnt4 signaling is specifically required for the activation of Lhx1, a transcriptional determinant of distal nephron cell fates (Kobayahi et al. 2005). Interestingly, this action can be mimicked by genetically elevating $\beta$-catenin levels, arguing for a continuing role for canonical Wnt signaling downstream from Wnt4 (Park et al. 2007). However, constitutive canonical pathway activation blocks MET suggesting a possible noncanonical component to Wnt4 action, a conclusion supported by recent analysis of the calcium/NFAT pathway in this process (Burn et al. 2011; Tanigawa et al. 2011). Together these data suggest a mechanism that may switch the signaling output to a Wnt4 input at different stages, or in different positions, of the developing RV. As to the cellular events that lead to MET, there is no good understanding of this epithelialforming process. Several cadherin-family members are activated at an early stage, including Cdh4 and Cdh6, but whereas some nephrons fail to form in Cdh6 mouse mutants, the kidneys are largely normal (Mah et al. 2000). Clearly, this is a rich area for future analysis, as are other cellular events dependent on RV induction. For example, $\mathrm{RV}$ induction feeds back in some way to promote further branching of the UB (Saxen 1987). In the absence of nephron formation, branching terminates prematurely-FGF, Wnt, and BMP signals are all good candidates for signals from induced mesenchyme that may promote, directly or indirectly, ureteric branching.

\subsection{Cessation of Nephrogenesis}

Between postnatal day (PD) 2 and 4 in the mouse, there is a final wave of nephrogenesis that appears to mark the 
terminal exhaustion of all remaining CM (Fig. 4) (Hartman et al. 2007; Brunskill et al. 2011; Rumballe et al. 2011). By PD 3, all Six2 ${ }^{+}$cells are lost and with this any capacity for normal de novo nephrogenesis, even in injured kidneys. What causes this cessation of nephrogenesis, and the apparent loss of CM self-renewal or an altered balance between self-renewal and commitment to differentiation, has not been determined. Two simple possibilities exist (Fig. 4). The first is an active trigger that ends CM self-renewal. Although this may be mediated by a change in gene expression either in the CM or an adjacent portion of the nephrogenic niche (Brunskill et al. 2011), it is not clear what might trigger such a change. A parturition-based signal (oxygen tension changes) has been proposed in mice based on gene expression changes within the CM (Brunskill et al. 2011). This would not explain the reported cessation of nephrogenesis in humans at 36 wk of pregnancy (Hinchliffe et al. 1991), although contrary reports suggest glomerulogenesis persists postnatally in full-term human infants (Gruenwald and Popper 1940; Faa et al. 2010). Alternatively, the termination of nephrogenesis may reflect a gradual depletion of the self-renewing fraction within the CM domain to the point that no true progenitors remain (Brunskill et al. 2011; Rumballe et al. 2011). Again this may result from a shift in growth factors within the niche surrounding the CM, a model evoking a progressive and inevitable process rather than a de novo-produced trigger. Given the large variation in nephron number observed in humans $(200,000$ to 1.8 million nephrons per kidney) (Hughson et al. 2003), and the well-established inverse association between nephron number and onset of renal disease in postnatal life (Brenner and Anderson 1992), an improved understanding of the limits to nephrogenesis may have important clinical ramifications.

\section{PATTERNING, SEGMENTATION, AND SPECIALIZATION OF THE EPITHELIAL NETWORKS}

The epithelial RV (also called a Stage I nephron) forms a lumen and begins to "unwind" to form comma-shaped and S-shaped bodies (Stage II nephrons), ultimately vascularizing at the proximal end into a capillary loop (Stage III) and finally mature nephron (Stage IV). The neonephron fuses with the ureteric tip shortly after the MET event as the first step in a poorly understood process that generates a continuous luminal interconnection between the two epithelial networks (Georgas et al. 2009). Interestingly, from the time that RVs are first observed, gene expression is polarized into proximal and distal gene expression domains:
A

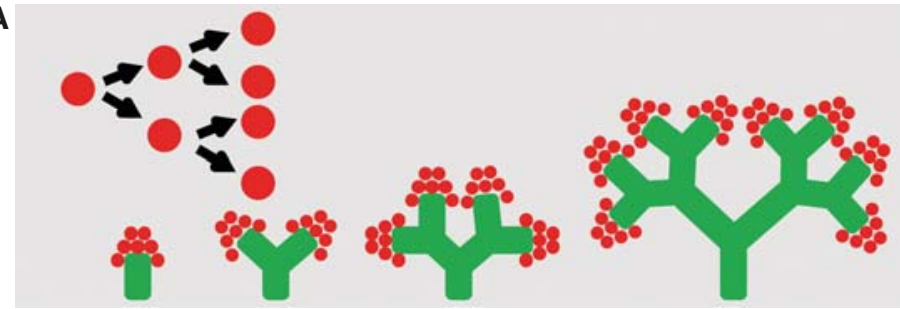

B

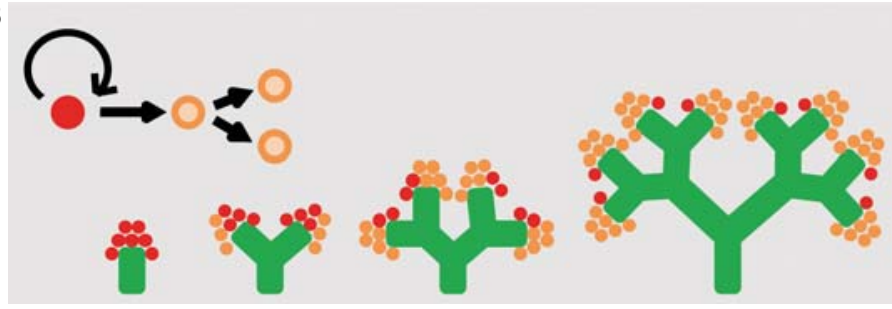

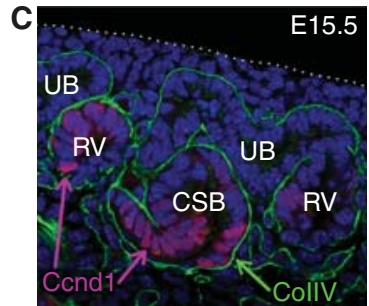

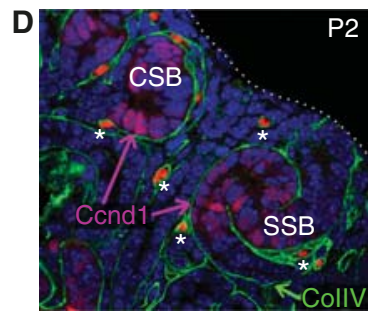

Figure 4. Cessation of nephrogenesis. Two models can be envisaged to explain cessation of nephrogenesis in the immediate postnatal period. (A) Symmetric division of a homogeneous progenitor population with an active trigger at birth to induce differentiation, and hence loss, of the progenitor population around birth. (B) A stem/progenitor subpopulation (red) within the cap mesenchyme that divides asymmetrically to self-renew and form more committed daughter cell populations (orange). This stem/progenitor population is distributed between the newly arising tips. This results in a gradual exhaustion of the stem/progenitor until they are lost. $(C, D)$ Coimmunofluroescence for dividing cells within the forming nephrons (Ccnd1; magenta), basement membrane (collagen IV [ColIV]; green) and nuclei (DAPI, blue) of kidney sections at E15.5 (C) and postnatal day 2 (P2) (D) illustrating the loss of cap mesenchyme and change in spatial relationships during cessation of nephrogenesis. Note: Isolated bright red dots in $D$ ${ }^{*}$ ) represent red blood cells in the forming vasculature. Ureteric bud (UB), renal vesicle (RV), comma-shaped body (CSB), S-shaped body (SSB). Dotted line illustrates the edge of the kidney. 
the latter adjacent to the UB, the former more distant $(\mathrm{Na}-$ kai et al. 2003; Kobayashi et al. 2005; Georgas et al. 2009; Mugford et al. 2009). Genes such as Lhxl and Pou3f3 occupy distal RV domains, whereas Wt1 expression becomes restricted to proximal regions. The distal expression of Notch (Dll1, Jag1), Bmp (Bmp2), and Wnt (Wnt4, Lef1, and $D k k 1)$ pathway genes implies different cellular identity and activity along the proximal-distal axis (Dressler et al. 2006; Kopan et al. 2007; Georgas et al. 2009; Mugford et al. 2009). Many of these genes are critical for specification of specific nephron segments. Notch signaling, predominantly Notch2, is critical for the elaboration of proximal nephron fates (podocytes and proximal tubules) (Cheng et al. 2007), whereas Lhxl regulates patterning of distal tubular structures (Kobayashi et al. 2005). Lhxl is upstream of Notch2, which in turn regulates the onset of expression of another distal RV gene, Cdh6 (Cheng et al. 2007). Notch ligands are expressed within the RV derivative, and their directional signaling may be promoted by the complex contortions that the RV undergoes during its morphogenesis from a RV to an S-shaped body. This period sees a rapid growth of the RV derivative; localized upregulation of cell-cycle targets is an early feature of the emerging proximal-distal polarity (Georgas et al. 2009), preceding elongation and folding of the tubular epithelium, and the emergence of de novo domains of gene expression that presage, and likely establish, the segmental organization of the adult nephron. For example, Pou $3 \mathrm{f3}$ (Brn1) expression is present in the distal and mid-regions of the S-shaped body where its action is essential for formation of loops of Henle, the renal tubular component that is critical for concentrating urine (Nakai et al. 2003). Thus, there is a marked cellular specialization and tubular elongation that characterizes the establishment of a functioning nephron. Interestingly, recent genetic evidence points to a second role for Wnt9b signals from the ureteric epithelium regulating the morphogenesis and lengthening of adjacent proximal tubule regions through convergent extension processes (Karner et al. 2009).

RV induction leads to a MET, one that does not immediately involve a classical E-cadherin (Cdh1) mechanism (Georgas et al. 2009). At later stages, the up-regulation of $\mathrm{Wt} 1$ in proximal nephron components of the RV derivative is associated with the exclusion of Cdh1 expression (Fig. 5). Surprisingly then, Wt1 had been positively associated with MET as MET is disrupted in Wilms' tumors, $10 \%-15 \%$ of
A
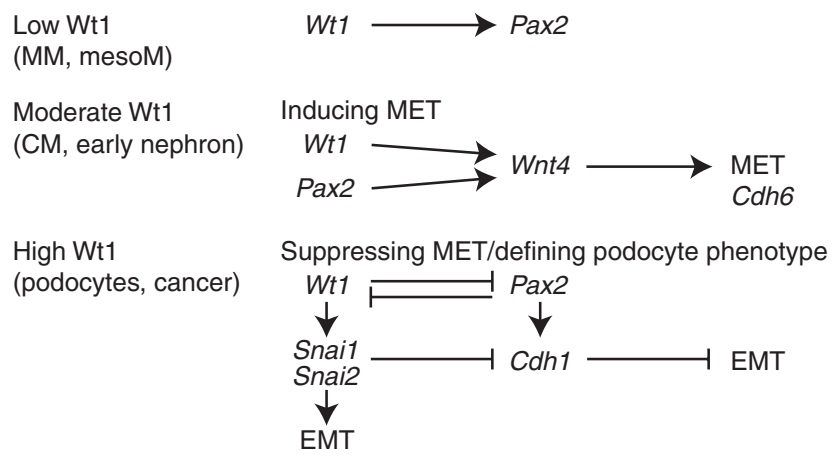

B

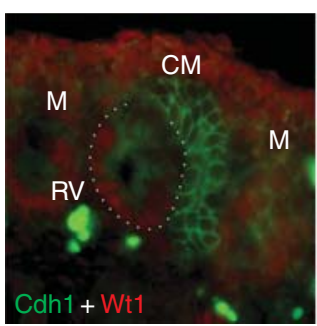

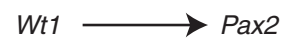

Inducing MET

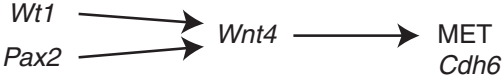

Suppressing MET/defining podocyte phenotype

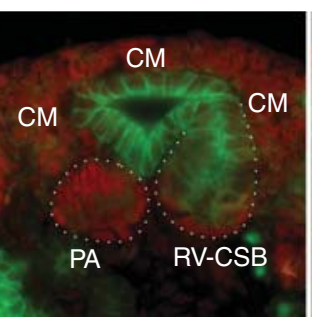

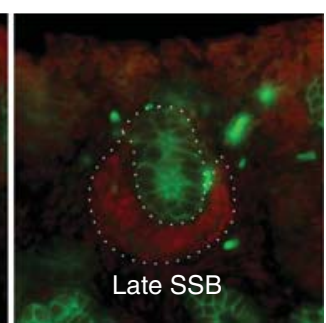

Figure 5. Inverse relationship between Wt1 and E-cadherin (Cdh1) during nephron segmentation. (A) Outline of the relationship between the level and location of Wt1 protein and the likely role of this protein during kidney development. (B) Coimmunofluorescence of E15.5 kidney illustrating the location of Wt1 (red) and E-cadherin (green) proteins during nephron formation and patterning. Cap mesenchyme (CM); renal vesicle (RV); pretubular aggregate (PA); comma-shaped body (CSB); S-shaped body (SSB). The ureteric epithelium expresses E-cadherin, whereas the surrounding $\mathrm{Wt}^{+} \mathrm{CM}$ does not. Nephron formation, which involves a mesenchyme-to-epithelial transition, it not uniform in that $\mathrm{E}$-cadherin is not seen in the $\mathrm{Wt}^{+}$proximal segments of the $\mathrm{RV}, \mathrm{CSB}$, or SSB. These regions form the parietal and visceral (podocyte) epithelia of the glomerulus. Mesenchyme-to-epithelial transition (MET); epithelial to mesenchymal transition (EMT); metanephric mesenchyme (MM); mesonephric mesenchyme (mesoM); cap mesenchyme (CM); mesenchyme (M). 
which result from inactivating mutations in the Wt1 gene (Little et al. 1992; Little and Wells 1997). There is also evidence that Wt1 positively regulates Wnt4 expression, promoting Wnt4-mediated epithelialization (Sim et al. 2002). However, Wt1 is also reported to support epithelial-to-mesenchymal transition (EMT), via the inhibition of E-cadherin and activation of Snail $/ 2$ during the formation of cardiac progenitors from the epicardial field (Fig. 5) (Martínez-Estrada 2010). An alternate explanation would be a role for Wt1 in maintaining a more plastic intermediate state capable of transition between epithelial and mesenchymal states. Indeed, the highest levels of Wt1 expression are observed in both developing and postnatal podocytes, a polarized arborized cell type unlike conventional tubular epithelium. The presence of focal segmental glomerulosclerosis and mesangial sclerosis in syndromes with WT1 dominant-negative mutations (Denys-Drash syndrome, Meacham syndrome) highlights the need for ongoing Wt1 expression in the postnatal podocyte population potentially enabling cytoskeletal plasticity or flexibility in this cell population.

The proximal RV gives rise to the glomerular epithelium, and the first gene specific to podocyte commitment in this region is Foxc2, which is expressed from the commashaped body stage (Takemoto et al. 2006). By the S-shaped body stage, there is a distinct separation of cellular morphology between those cells fated to be podocytes and those forming parietal epithelial cells of Bowman's capsule, coinciding with the expression of $L m x 1 b$, Podxl, Nphsl, and Nphs2 in the presumptive podocytes (Takemoto et al. 2006). These cells also begin to express high levels of Vegfa, attracting an angioblast population from the surrounding interstitium to form glomerular capillaries. An elegant series of mutants that varied Vegfa protein production in podocytes highlights the critical role of Vegfa signaling in forming the capillary bed (Eremina et al. 2003, 2007). Glomerular formation is also regulated by Bmp4 in podocytes, and PdgfB/Pdgfrb pathway controls mesangial cell recruitment (Lindahl et al. 1998; Ueda et al. 2008). The intricate specialization and polarization of podocytes, essential to the elaboration of slit diaphragms, is multifactorial and highly complex. However, expression of Wt1 persists here throughout life, presumably orchestrating this event. Although few specific Wt1 targets have been defined in the podocyte, the $\mathrm{Wt}^{+}{ }^{+} \mathrm{KTS}$ isoform regulates expression of Scribbled homolog (Scrb), a key protein in cellular polarity (Wells et al. 2010). Continued expression of both Vegfa and $\mathrm{Wtl}$ are required for maintaining podocyte morphology. The conditional removal of Drosha and Dicerl from podocytes also suggests an ongoing requirement for miRNA regulation (Harvey et al. 2008; Ho et al. 2008; Shi et al. 2008; Zhdanova et al. 2011). The subsequent interaction between the podocytes and the glomerular endothelium to form a functional glomerular basement membrane requires the coordination of large numbers of intracellular cytoskeletal elements, surface integrins, and extracellular laminins. For excellent reviews, we refer the reader to Ballerman 2005, Miner 2005, Quaggin and Kriedberg 2008, and Simons et al. 2009.

\subsection{Patterning and Functionalization of the Collecting Ducts}

The collecting duct network, which develops from the ureteric epithelium, also undergoes a distinct morphogenesis and cell specialization critical to renal function. Although the formation of the collecting system is frequently regarded as continuous dichotomous branching, there is considerable elongation of the collecting ducts in the latter part of kidney development. Wnt7b is largely restricted to medullary collecting ducts. Interestingly, whereas Wnt7b mutants show a normal cortical program of ureteric growth and branching, they show a complete failure in elongation of the medullary collecting duct, and the medullarydirected elongation of loops-of-Henle in adjacent maturing nephrons (Yu et al. 2009). Via canonical Wnt signaling, Wnt7b appears to govern orientated cell divisions that are predicted to favor formation and continued elaboration of the medullary collecting duct network (Yu et al. 2009). Medullary morphogenesis coincides with the expression of medullary collecting duct genes reflecting the distinct functional maturation of these structures for water reabsorption and acid/base balance. This includes the differentiation of Aqp $2^{+}$principal cells and vacuolar $\mathrm{H}^{+}$-ATPase ${ }^{+}$ intercalated cells. Although such markers are initially coexpressed, the onset of Foxil expression in a subset of collecting duct cells appears to impose an intercalated cell phenotype onto a presumably bipotential progenitor (Blomqvist et al. 2004). A number of defects have now been described in which this is disrupted, including the deletion of a Notch signaling antagonist, Mib1 (Joeng et al. 2009), and the absence of Foxil itself. Another important feature of collecting duct maturation is the separation between $\mathrm{Aqp}^{+}{ }^{+}$water reabsorbing collecting ducts and the uroplakin $^{+}$water-impermeable epithelium lining the pelvis and ureter. Urinary filtrate removal also requires the development of appropriate peristalsis, originating from a pacemaker at the base of the papilla, and ureteric contractility, requiring the investment of smooth muscle around the ureter. Sonic hedgehog (Shh) signaling has long been recognized as playing a critical role in these processes ( $\mathrm{Yu}$ et al. 2002). Shh is secreted from the medullary collecting duct and ureteric stalk and signals to the Ptch1 receptor in the surrounding interstitium (Yu et al. 2002). Bmp4 
expression in this interstitium induces uroplakin expression (Brenner-Anantharam et al. 2007) and Bmp4/Shh together induce the transcription factor Tshz3, a regulator of smooth muscle investment (Caubit et al. 2008). Tbx18 appears to be upstream of both Shh and Bmp4 in regulating ureteral mesenchyme development (Airik et al. 2006). Mutations in Shh pathway components (Smo, Ptch1, Shh, and the repressor Gli3) generate a wide variety of hypoplastic and dysplastic phenotypes indicating that pathway action is complex (Hu et al. 2006; Cain et al. 2009, Cain and Rosenblum 2011). As loss of Gli3 results in inappropriate Hedgehog pathway activation in any responsive cell type, some phenotypes likely reflect neomorphic actions rather than the normal action of hedgehog signals. Consistent with the important silencing function of Gli3, mutations in GLI3 in patients with Pallister-Hall syndrome can result in renal agenesis, hypoplasia, or hydronephrosis (Hall et al. 1980; Pallister et al. 1989).

As highlighted above, tubule length, elongation, and shape are critical for normal renal function. Altered planes of cell division are likely to disturb tubular patterning and hence play a critical role in renal disease, most notably in the etiology of polycystic kidney disease (PKD). Autosomal dominant PKD is the most common autosomal dominant disease in the human population and results from a loss-of-function of PKD1 (European Polycystic Kidney Disease Consortium 1994). Recessive forms of PKD also exist, as do a wide number of other cystic diseases of the kidney and liver, all of which converge on signaling components that couple to the primary cilium, a critical sensory node within the epithelial cell. Consequently, cystic kidney disease associates with a range of ciliopathies. The genetic basis of such ciliopathies is an area that has expanded enormously based on the identification of cilia-associated genes in the worm Caenorhabditis elegans. Convergence of the Shh and Wnt pathways on primary cilia tends to again implicate these key pathways in cyst formation. This is an extensive body of literature, and hence we would refer the reader to specific reviews of this area (see Guay-Woodford 2003; Harris and Torres 2009; Hurd and Hildebrandt 2011; Muller et al. 2011).

\section{POSTNATAL EVENTS IN FUNCTIONAL RENAL MATURATION}

Although nephrogenesis is over shortly after birth in the mouse, the newborn kidney remains functionally primitive with respect to the capacity to concentrate urine, control acid-base balance, and reabsorb filtered nutrients. Indeed, a substantial amount of tubular elongation occurs in the proximal tubules, loops of Henle, and the collecting ducts after birth in a variety of mammalian species. The molecular basis of maturation during this period of time remains very poorly understood and underinvestigated. However, genetic events linked to some defects have been identified. For example, the proximal tubule plays an important role in the reclamation of amino acids through selective amino acid transporters. A defect in the reabsorption of imino groups (proline and hydroxyproline) and glycine is observed in patients with iminoglycinuria. In the human kidney, these amino acids are reclaimed by specific solute channels, including SLC36A2, SLC6A20, and SLC6A18. SLC6A19 transports neutral amino acids (tryptophan and histidine) with mutations causing the recessive metabolic Hartnup disorder (Kleta et al. 2004; Seow et al. 2004). A form of transient iminoglycinuria exists in some neonates. Although expressed at low levels in the first week of life, the SLC36A2 isoform present is an inactive transporter that does not reach the apical membrane, explaining the significant shedding of imino acid moieties at this time. Effective delivery of this and other transporters (Slc6a20a and Slc6a18) to the apical surface does not occur until postnatal day 7 in the mouse (Vanslamsbrouck et al. 2010). Amino acid shedding continues for $2-3 \mathrm{wk}$, potentially owing to the coincident delay in the expression and cytoplasmic localization of collectrin (Tmem27) and Ace2, accessory proteins required for murine transporter function (Vanslamsbrouck et al. 2010).

\section{REASSESSING RENAL DISEASE, REPAIR, AND REGENERATION USING DEVELOPMENTAL BIOLOGY}

Although there is a significant need to fill the gaps in our knowledge of the final steps in maturation of mammalian kidney function, there is also a significant disconnect between our understanding of fetal kidney development and the normal response of the adult kidney to damage. No new nephrons arise in the adult kidney. Indeed, the adult kidney is not a regenerative organ like the liver; no regrowth follows resection. However, tubular damage, notably in response to acute injury resulting from sepsis, ischemia, or nephrotoxic drugs, is repaired. Reexpression of key developmental genes during renal injury, including Bmp7, Notch1/2 genes, Noggin (Nog), Shh, and Pax2 (Vilaneuva et al. 2006; Cohen et al. 2007) has been reported. However, this does not necessarily indicate a reparative role and can simply reflect a pathological loss of cellular identity. A long literature exists proposing that dedifferentiation of the tubular epithelium does occur in renal disease, as evidenced by the loss of epithelial markers within the cells of damaged tubules. Whether dedifferentiating cells return to an earlier developmental state has not been rigorously addressed. Stem or progenitor populations 
within tubules, or elsewhere in the kidney, have been postulated to govern repair processes. Ischemic reperfusion injury performed on CM lineage-tracing mice (Six2GFPCre) (Kobayashi et al. 2008) suggest that the predominant repair process is driven by cells within the CM-derived nephron epithelium, but that reinitiation of Six2 expression does not accompany the repair process (Humphreys et al. 2008). Although lending support to a within-tubule repair system, the experiments do not address whether all cells have repair potential, as opposed to a repair process directed by a rare, tubule progenitor type. However, cell proliferation on damage appears to be a general property of surviving epithelial cells in the repairing nephron (Vogetseder et al. 2007; Humphreys et al. 2011). This is in line with studies that argue that the tubular epithelium itself, although not inherently proliferative, rests in G1 rather than G0, placing it in a primed position to progress through cell division if triggered to do so (Vogetseder et al. 2007).

Not all regions of the kidney may behave alike. Acute injury models in the mouse largely affect proximal tubule regions; chronic models focus on the podocyte. A specific $\mathrm{CD} 24^{+} \mathrm{CD} 133^{+}$population of epithelial cells in Bowman's capsule appears to differentiate into podocalyxin (Pdxl1)positive podocytes that migrate onto the vascular stalk (Appel et al. 2009; Ronconi et al. 2009) suggesting that these $\mathrm{CM}$ derivatives remain plastic, allowing for the turnover of podocytes throughout adult life. Determining whether this represents a limited niche-specific response or whether these cells have more general repair properties awaits further study. Valuable lessons may also be learned from looking laterally at vertebrates that do things differently. In the zebrafish, as with other teleosts, the adult kidney generates and regenerates nephrons. Recent work indicates that regenerative potential resides with a Six $2^{+} \mathrm{Lhx} 1^{+-}$ mesenchymal cell type not observed in the mammalian kidney (Diep et al. 2011).

\subsection{The Cellular Origin of Progressive Renal Fibrosis}

Another aspect of renal disease that has directly benefited from the application of genetic tools is the ontogeny of fibrosis in progressive renal disease. It has long been held that the accumulation of interstitial fibrosis in response to almost all chronic damage signals results from an epithelial-to-mesenchymal transition of renal tubular epithelial cells, exacerbated via Tgf $\beta 1$ secretion and antagonized by Bmp7. This was first challenged by Zeisberg et al. (2008) who used Tie2-Cre;R26R-stop-EYFP mice to show evidence for an endothelial origin for approximately $30 \%-50 \%$ of the interstitial fibroblasts in mice treated with a variety of genetic (Alport syndrome) or environmental (streptozocin-induced diabetes, ureteric obstruction) damage signals. This was corroborated by Li et al. (2009). It has also been shown that the initial infiltrating bone marrow-derived macrophage population seen in a damaged kidney can ultimately contribute to the $\alpha$ SMA-positive expanded interstitium of a damaged kidney (Li et al. 2007). Most recently, Humphreys et al. (2010) have shown that fibrosis in a ureteral obstruction model genetically maps to Foxd1-derived, not Six2-derived, cell types. These data, together with analyses of pericyte markers, suggest an interstitial mesenchyme/pericyte origin for much of the fibrotic outcome in this injury. Given the strong correlation of fibrosis with end-stage kidney disease, understanding how these events may be prevented is a central goal in translating basic research to improved clinical outcome.

\section{LOOKING TO THE FUTURE}

Over the last decade, a general outline of many of the key mechanisms driving mammalian kidney development has emerged, although many basic questions remain: lineage relationships and the differential roles of stem/progenitor compartments in development and injury repair; determinative versus stoichiometric control of branching growth; mechanisms that couple epithelial joining of the newly formed nephron to the collecting duct; determining the size and shape of the kidney and the number of nephrons; how nephron polarity and segmentation is controlled; and the mechanisms that coordinate assembly of distinct cellular compartments, such as vascular and nephron epithelia, into a working kidney.

Large-scale resources such as the GUDMAP initiative (McMahon et al. 2008; Harding et al. 2011; www. gudmap.org) have generated a wealth of valuable new data that is impacting the field. An understanding of the mechanisms controlling nephron polarity, tubular morphogenesis, and regional specialization of cell types in the nephron has been greatly facilitated by the identification and characterization of molecular markers to study these events through systematic gene expression studies (Brunskill et al. 2008; Thiagarajan et al. 2011). As an example, $>35$ compartment specific genes have been identified intricately subdividing across time and space the process of renal tubular differentiation (Thiagarajan et al. 2011). The genes identified through these studies not only serve as helpful markers to dissect the events at play, but as potential regulatory players in their own right, and useful loci for the development of new genetic tools to dissect these intriguing biological processes. The continuing integration of gene expression data into genetic and cellular programs of kidney development is an important task for the future.

Without the genetic tools developed to date, progress would have been very different. In vivo genetic analysis 
will continue to play a leading role in these studies. The generation of finer and finer tools to increase the range, precision, and timing of genetic modification, and the generation of new models that closely reflect clinical disease, is imperative. These approaches will not only enhance our knowledge base, but will also facilitate the design of clinical approaches well grounded in a deep and rigorous understanding of the organ system. Developmental studies have identified secreted growth factors such as BMP7 (OP1) that show clinical promise. Development-based discovery is likely to play an increasingly important role in generating clinical opportunities.

Cell culture studies will complement in vivo studies. Current planar explant culture systems compromise our understanding of important cellular processes such as branching morphogenesis, segmental convolution, and papillary extension; a particular challenge given the late onset of medullary modeling. New culture systems that can greatly extend the normal developmental life of the kidney in vitro, provide $3 \mathrm{D}$ information, and incorporate detailed cellular imaging are a priority.

Although the generation of induced pluripotent stem cells (iPSCs) from patients is now routine, the in vitro differentiation and maintenance of clinically relevant renal cell types is not, hampering the ability to develop in vitro models of human disease. For example, no long-term culture systems exist that can propagate $\mathrm{Six} 2^{+}$nephron progenitors, or support the normal properties of podocytes or proximal tubular epithelial cell types, both critical mediators of normal kidney function and targets of the disease process. The bolder approach of reconstructing a bioengineered kidney, once considered implausible, may be possible, but not without improved culture systems. A divide exists between development and renal physiology-what is really required for a kidney to work. Intersecting developmental biology, experimental nephrology, renal physiology, and renal medicine will close this gap.

\section{ACKNOWLEDGMENTS}

M.H.L. is an NHMRC Principal Research Fellow. Work in APM's laboratory is supported by grants from the NIDDK at the NIH. We thank Kylie Georgas for assistance in the creation of figures.

\section{REFERENCES}

Abrahamson DR, Robert B. 2003. Derivation and differentiation of glomerular endothelial cells. Nephrol Dial Transplant 18: vi2-vi7.

Airik R, Bussen M, Singh MK, Petry M, Kispert A. 2006. Tbx18 regulates the development of the ureteral mesenchyme. J Clin Invest 116: 663674.

Angers S, Moon RT. 2009. Proximal events in Wnt signal transduction. Nat Rev Mol Cell Biol 10: 468-477.
Appel D, Kershaw DB, Smeets B, Yuan G, Fuss A, Frye B, Elger M, Kriz W, Floege J, Moeller MJ. 2009. Recruitment of podocytes from glomerular parietal epithelial cells. J Am Soc Nephrol 20: 333-343.

Ballermann BJ. 2005. Glomerular endothelial cell differentiation. Kidney Int 67: $1668-1671$.

Basson MA, Watson-Johnson J, Shakya R, Akbulut S, Hyink D, Costantini FD, Wilson PD, Mason IJ, Licht JD. 2006. Branching morphogenesis of the ureteric epithelium during kidney development is coordinated by the opposing functions of GDNF and Sproutyl. Dev Biol 299: 466-477.

Bates CM. 2011. Role of fibroblast growth factor receptor signaling in kidney development. Am J Physiol Renal Physiol 301: F245-F251.

Blomqvist SR, Vidarsson H, Fitzgerald S, Johansson BR, Ollerstam A, Brown R, Persson AE, Bergström G G, Enerbäck S. 2004. Distal renal tubular acidosis in mice that lack the forkhead transcription factor Foxil. J Clin Invest 113: 1560-1570.

Bouchard M, de Caprona D, Busslinger M, Xu P, Fritzsch B. 2002. Nephric lineage specification by Pax2 and Pax8. Genes Dev 16: 2958-2970.

Boyle S, Shioda T, Perantoni AO, de Caestecker M. 2007. Cited1 and Cited2 are differentially expressed in the developing kidney but are not required for nephrogenesis. Dev Dyn 236: 2321-2330.

Boyle S, Misfeldt A, Chandler KJ, Deal KK, Southard-Smith EM, Mortlock DP, Baldwin HS, de Caestecker M. 2008. Fate mapping using Cited1-CreERT2 mice demonstrates that the cap mesenchyme contains self-renewing progenitor cells and gives rise exclusively to nephronic epithelia. Dev Biol 313: 234-245.

Brenner BM, Anderson S. 1992. The interrelationships among filtration surface area, blood pressure, and chronic renal disease. J Cardiovasc Pharmacol 19: S1-S7.

Brenner-Anantharam A, Cebrian C, Guillaume R, Hurtado R, Sun TT, Herzlinger D. 2007. Tailbud-derived mesenchyme promotes urinary tract segmentation via BMP4 signaling. Development 134: 1967-1975.

Bridgewater D, Rosenblum ND. 2009. Stimulatory and inhibitory signaling molecules that regulate renal branching morphogenesis. Pediatr Nephrol 24: 1611-1619.

Brodbeck S, Englert C. 2004. Genetic determination of nephrogenesis: The Pax/Eya/Six gene network. Pediatr Nephrol 19: 249-255.

Brodbeck S, Besenbeck B, Englert C. 2004. The transcription factor Six2 activates expression of the Gdnf gene as well as its own promoter. Mech Dev 121: $1211-1222$.

Brunskill EW, Aronow BJ, Georgas K, Rumballe B, Valerius MT, Aronow J, Kaimal V, Jegga AG, Yu J, Grimmond S, et al. 2008. Atlas of gene expression in the developing kidney at microanatomic resolution. Dev Cell 15: 781-791.

Brunskill EW, Lai HL, Jamison DC, Potter SS, Patterson LT. 2011. Microarrays and RNA-Seq identify molecular mechanisms driving the end of nephron production. BMC Dev Biol 11: 15.

Burn SF, Webb A, Berry RL, Davies JA, Ferrer-Vaquer A, Hadjantonakis AK, Hastie ND, Hohenstein P. 2011. Calcium/NFAT signalling promotes early nephrogenesis. Dev Biol 352: 288-298.

Cai Y, Brophy PD, Levitan I, Stifani S, Dressler GR. 2003. Groucho suppresses Pax2 transactivation by inhibition of JNK-mediated phosphorylation. EMBO J 22: 5522-5529.

Cain JE, Rosenblum ND. 2011. Control of mammalian kidney development by the Hedgehog signaling pathway. Pediatr Nephrol 26: 13651371.

Cain JE, Islam E, Haxho F, Chen L, Bridgewater D, Nieuwenhuis E, Hui CC, Rosenblum ND. 2009. GLI3 repressor controls nephron number via regulation of Wnt11 and Ret in ureteric tip cells. PLoS One 4: e7313.

Caricasole A, Duarte A, Larsson SH, Hastie ND, Little M, Holmes G, Todorov I, Ward A. 1996. RNA binding by the Wilms tumor suppressor zinc finger proteins. Proc Natl Acad Sci 93: 7562-7566.

Carroll TJ, McMahon AP. 2003. Overview: The molecular basis of kidney development. In The kidney: From normal development to congenital disease (ed. Vize PD, et al.), pp. 343-376. Academic Press, London. 
Carroll TJ, Park JS, Hayashi S, Majumdar A, McMahon AP. 2005. Wnt9b plays a central role in the regulation of mesenchymal to epithelial transitions underlying organogenesis of the mammalian urogenital system. Dev Cell 9: 283-292.

Caubit X, Lye CM, Martin E, Coré N, Long DA, Vola C, Jenkins D, Garratt AN, Skaer H, Woolf AS, et al. 2008. Teashirt 3 is necessary for ureteral smooth muscle differentiation downstream of SHH and BMP4. Development 135: 3301-3310.

Cheng HT, Kim M, Valerius MT, Surendran K, Schuster-Gossler K, Gossler A, McMahon AP, Kopan R. 2007. Notch2, but not Notch1, is required for proximal fate acquisition in the mammalian nephron. Development 134: 801-811.

Chi X, Hadjantonakis AK, Wu Z, Hyink D, Costantini F. 2009a. A transgenic mouse that reveals cell shape and arrangement during ureteric bud branching. Genesis 47: 61-66.

Chi X, Michos O, Shakya R, Riccio P, Enomoto H, Licht JD, Asai N, Takahashi M, Ohgami N, Kato M, et al. 2009b. Ret-dependent cell rearrangements in the Wolffian duct epithelium initiate ureteric bud morphogenesis. Dev Cell 17: 199-209.

Cohen T, Loutochin O, Amin M, Capolicchio JP, Goodyer P, Jednak R. 2007. PAX2 is reactivated in urinary tract obstruction and partially protects collecting duct cells from programmed cell death. Am J Physiol Renal Physiol 292: F1267-F1273.

Costantini F, Kopan R. 2010. Patterning a complex organ: Branching morphogenesis and nephron segmentation in kidney development. Dev Cell 18: 698-712.

Diep CQ, Ma D, Deo RC, Holm TM, Naylor RW, Arora N, Wingert RA, Bollig F, Djordjevic G, Lichman B, et al. 2011. Identification of adult nephron progenitors capable of kidney regeneration in zebrafish. $\mathrm{Na}$ ture 470: 95-100.

Dressler GR. 2006. The cellular basis of kidney development. Annu Rev Cell Dev Biol 22: 509-529.

Dudley AT, Lyons KM, Robertson EJ. 1995. A requirement for bone morphogenetic protein-7 during development of the mammalian kidney and eye. Genes Dev 9: 2795-2807.

Dudley AT, Godin RE, Robertson EJ. 1999. Interaction between FGF and BMP signaling pathways regulates development of metanephric mesenchyme. Genes Dev 13: 1601-1613.

Eremina V, Sood M, Haigh J, Nagy A, Lajoie G, Ferrara N, Gerber HP, Kikkawa Y, Miner JH, Quaggin SE. 2003. Glomerular-specific alterations of VEGF-A expression lead to distinct congenital and acquired renal diseases. J Clin Invest 111: 707-716.

Eremina V, Baelde HJ, Quaggin SE. 2007. Role of the VEGF-A signaling pathway in the glomerulus: Evidence for crosstalk between components of the glomerular filtration barrier. Nephron Physiol 106: p32p37.

European Polycystic Kidney Disease Consortium. 1994. The polycystic kidney disease 1 gene encodes a $14 \mathrm{~kb}$ transcript and lies within a duplicated region on chromosome 16. Cell 77: 881-894.

Faa G, Gerosa C, Fanni D, Nemolato S, Locci A, Cabras T, Martinelli V, Puddu M, Zaffanello M, Monga G, et al. 2010. Marked interindividual variability in renal maturation of preterm infants: Lessons from autopsy. J Matern-Fetal Neo M 23: 129-133.

Gao X, Chen X, Taglienti M, Rumballe B, Little MH, Kreidberg JA. 2005. Angioblast-mesenchyme induction of early kidney development is mediated by Wt1 and Vegfa. Development 132: 5437-5449.

Georgas KM, Rumballe BA, Valerius MT, Chiu HS, Thiagarajan RD, Lesieur E, Aronow BJ, Brunskill EW, Combes AN, Tang D, et al. 2009. Analysis of early nephron patterning reveals a role for distal RV proliferation in fusion to the ureteric tip via a cap mesenchyme-derived connecting segment. Dev Biol 332: 273-286.

Gong KQ, Yallowitz AR, Sun H, Dressler GR, Wellik DM. 2007. A Hox-Eya-Pax complex regulates early kidney developmental gene expression. Mol Cell Biol 27: 7661-7668.

Grieshammer U, Le Ma, Plump AS, Wang F, Tessier-Lavigne M, Martin GR. 2004. SLIT2-mediated ROBO2 signaling restricts kidney induction to a single site. Dev Cell 6: 709-717.
Grieshammer U, Cebrian C, Ilagan R, Meyers E, Herzlinger D, Martin GR. 2005. FGF8 is required for cell survival at distinct stages of nephrogenesis and for regulation of gene expression in nascent nephrons. Development 132: $3847-3857$.

Grote D, Souabni A, Busslinger M, Bouchard M. 2006. Pax 2/8-regulated Gata 3 expression is necessary for morphogenesis and guidance of the nephric duct in the developing kidney. Development 133: 53-61.

Gruenwald P, Popper H. 1940. The histogenesis and physiology of the renal glomerulus in early postnatal life. J Urol 43: 452-466.

Guay-Woodford LM. 2003. Murine models of polycystic kidney disease: Molecular and therapeutic insights. Am J Physiol Renal Physiol 285: F1034-F1049.

Hall JG, Pallister PD, Clarren SK, Beckwith JB, Wiglesworth FW, Fraser FC, Cho S, Benke PJ, Reed SD. 1980. Congenital hypothalamic hamartoblastoma, hypopituitarism, imperforate anus and postaxial polydactyly-A new syndrome? Part I: Clinical, causal, and pathogenetic considerations. Am J Med Genet 7: 47-74.

Harding SD, Armit C, Armstrong J, Brennan J, Cheng Y, Haggarty B, Houghton D, Lloyd-Macgilp S, Pi X, Roochun Y, et al. 2011. The GUDMAP database-An online resource for genitourinary research. Development 138: 2845-2853.

Harris PC, Torres VE. 2009. Polycystic kidney disease. Annu Rev Med 60: 321-337.

Hartman HA, Lai HL, Patterson LT. 2007. Cessation of renal morphogenesis in mice. Dev Biol 310: 379-387.

Harvey SJ, Jarad G, Cunningham J, Goldberg S, Schermer B, Harfe BD, McManus MT, Benzing T, Miner JH. 2008. Podocyte-specific deletion of dicer alters cytoskeletal dynamics and causes glomerular disease. $J$ Am Soc Nephrol 19: 2150-2158.

Hatini V, Huh SO, Herzlinger D, Soares VC, Lai E. 1996. Essential role of stromal mesenchyme in kidney morphogenesis revealed by targeted disruption of Winged Helix transcription factor BF-2. Genes Dev 10: $1467-1478$

Hinchliffe SA, Sargent PH, Howard CV, Chan YF, van Velzen D. 1991. Human intrauterine renal growth expressed in absolute number of glomeruli assessed by the disector method and Cavalieri principle. Lab Invest 64: 777-784.

Ho J, Ng KH, Rosen S, Dostal A, Gregory RI, Kreidberg JA. 2008. Podocyte-specific loss of functional microRNAs leads to rapid glomerular and tubular injury. J Am Soc Nephrol 19: 2069-2075.

Hu MC, Mo R, Bhella S, Wilson CW, Chuang PT, Hui CC, Rosenblum ND. 2006. GLI3-dependent transcriptional repression of Gli1, Gli2 and kidney patterning genes disrupts renal morphogenesis. Development 133: 569-578.

Hughson M, Farris AB III, Douglas-Denton R, Hoy WE, Bertram JF. 2003. Glomerular number and size in autopsy kidneys: The relationship to birth weight. Kidney Int 63: 2113-2122.

Humphreys BD, Valerius MT, Kobayashi A, Mugford JW, Soeung S, Duffield JS, McMahon AP, Bonventre JV. 2008. Intrinsic epithelial cells repair the kidney after injury. Cell Stem Cell 2: 284-291.

Humphreys BD, Lin SL, Kobayashi A, Hudson TE, Nowlin BT, Bonventre JV, Valerius MT, McMahon AP, Duffield JS. 2010. Fate tracing reveals the pericyte and not epithelial origin of myofibroblasts in kidney fibrosis. Am J Pathol 176: 85-97.

Humphreys BD, Czerniak S, Dirocco DP, Hasnain W, Cheema R, Bonventre JV. 2011. Repair of injured proximal tubule does not involve specialized progenitors. Proc Natl Acad Sci 108: 9226-9231.

Hurd TW, Hildebrandt F. 2011. Mechanisms of nephronophthisis and related ciliopathies. Nephron Exp Nephrol 118: e9-e14.

Hyink DP, Tucker DC, St John PL, Leardkamolkarn V, Accavitti MA, Abrass CK, Abrahamson DR. 1996. Endogenous origin of glomerular endothelial and mesangial cells in grafts of embryonic kidneys. Am J Physiol 270: F886-F899.

Ishibe S, Karihaloo A, Ma H, Zhang J, Marlier A, Mitobe M, Togawa A, Schmitt R, Czyczk J, Kashgarian M, et al. 2009. Met and the epidermal growth factor receptor act cooperatively to regulate final nephron 
number and maintain collecting duct morphology. Development 136: $337-345$.

Jain S. 2009. The many faces of RET dysfunction in kidney. Organogenesis 5: $95-108$.

Jain S, Encinas M, Johnson EM Jr, Milbrandt J. 2006. Critical and distinct roles for key RET tyrosine docking sites in renal development. Genes Dev 20: 321-333.

Jain S, Knoten A, Hoshi M, Wang H, Vohra B, Heuckeroth RO, Milbrandt J. 2010. Organotypic specificity of key RET adaptor-docking sites in the pathogenesis of neurocristopathies and renal malformations in mice. J Clin Invest 120: 778-790.

James RG, Kamei CN, Wang Q, Jiang R, Schultheiss TM. 2006. Oddskipped related 1 is required for development of the metanephric kidney and regulates formation and differentiation of kidney precursor cells. Development 133: 2995-3004.

Jeong HW, Jeon US, Koo BK, Kim WY, Im SK, Shin J, Cho Y, Kim J, Kong YY. 2009. Inactivation of Notch signaling in the renal collecting duct causes nephrogenic diabetes insipidus in mice. J Clin Invest 119: 3290-3300.

Karner CM, Chirumamilla R, Aoki S, Igarashi P, Wallingford JB, Carroll TJ. 2009. Wnt9b signaling regulates planar cell polarity and kidney tubule morphogenesis. Nat Genet 41: 793-799.

Karner CM, Das A, Ma Z, Self M, Chen C, Lum L, Oliver G, Carroll TJ. 2011. Canonical Wnt9b signaling balances progenitor cell expansion and differentiation during kidney development. Development 138: $1247-1257$.

Kleta R, Romeo E, Ristic Z, Ohura T, Stuart C, Arcos-Burgos M, Dave MH, Wagner CA, Camargo SR, Inoue S. 2004. Mutations in SLC6A19, encoding B0AT1, cause Hartnup disorder. Nat Genet 36: 999-1002.

Kobayashi A, Kwan KM, Carroll TJ, McMahon AP, Mendelsohn CL, Behringer RR. 2005. Distinct and sequential tissue-specific activities of the LIM-class homeobox gene Lim1 for tubular morphogenesis during kidney development. Development 132: 2809-2823.

Kobayashi A, Valerius MT, Mugford JW, Carroll TJ, Self M, Oliver G, McMahon AP. 2008. Six2 defines and regulates a multipotent selfrenewing nephron progenitor population throughout mammalian kidney development. Cell Stem Cell 3: 169-181.

Kopan R, Cheng HT, Surendran K. 2007. Molecular insights into segmentation along the proximal-distal axis of the nephron. J Am Soc Nephrol 18: 2014-2020.

Kreidberg JA, Sariola H, Loring JM, Maeda M, Pelletier J, Housman D, Jaenisch R. 1993. WT-1 is required for early kidney development. Cell 74: 679-691.

Kume T, Deng K, Hogan BL. 2000. Murine forkhead/winged helix genes Foxc1 (Mf1) and Foxc2 (Mfh1) are required for the early organogenesis of the kidney and urinary tract. Development 127: 1387-1395.

Kuure S, Cebrian C, Machingo Q, Lu BC, Chi X, Hyink D, D’Agati V, Gurniak C, Witke W, Costantini F. 2010. Actin depolymerizing factors cofilin 1 and destrin are required for ureteric bud branching morphogenesis. PLoS Genet 6: e1001176.

Larsson SH, Charlieu JP, Miyagawa K, Engelkamp D, Rassoulzadegan M, Ross A, Cuzin F, van Heyningen V, Hastie ND. 1995. Subnuclear localization of WT1 in splicing or transcription factor domains is regulated by alternative splicing. Cell 81: 391-401.

Li J, Deane JA, Campanale NV, Bertram JF, Ricardo SD. 2007. The contribution of bone marrow-derived cells to the development of renal interstitial fibrosis. Stem Cells 25: 697-706.

Li J, Qu X, Bertram JF. 2009. Endothelial-myofibroblast transition contributes to the early development of diabetic renal interstitial fibrosis in streptozotocin-induced diabetic mice. Am J Pathol 175: 1380-1388.

Lim KC, Lakshmanan G, Crawford SE, Gu Y, Grosveld F, Engel JD. 2000. Gata3 loss leads to embryonic lethality due to noradrenaline deficiency of the sympathetic nervous system. Nat Genet 25: 209-212.

Lindahl P, Hellstrom M, Kalen M, Karlsson L, Pekny M, Pekna M, Soriano P, Betsholtz C. 1998. Paracrine PDGF-B/PDGF-R $\beta$ signaling controls mesangial cell development in kidney glomeruli. Development 125: $3313-3322$
Little M, Wells C. 1997. A clinical overview of WT1 gene mutations. Hum Mutat 9: 209-225.

Little MH, Prosser J, Condie A, Smith PJ, Van Heyningen V, Hastie ND. 1992. Zinc finger point mutations within the WT1 gene in Wilms tumor patients. Proc Natl Acad Sci 89: 4791-4795.

Little M, Holmes G, Walsh P. 1999. WT1: What has the last decade told us? Bioessays 21: 191-202.

Lu BC, Cebrian C, Chi X, Kuure S, Kuo R, Bates CM, Arber S, Hassell J, MacNeil L, Hoshi M, et al. 2009. Etv4 and Etv5 are required downstream of GDNF and Ret for kidney branching morphogenesis. Nat Genet 41: 1295-1302.

Lusis M, Li J, Ineson J, Li J, Little MH. 2010. Isolation and culture of metanephric mesenchyme-derived nephrospheres reinforces evidence that embryonic renal progenitors are multipotent and exhaust during cessation of nephron formation. Stem Cell Res 5: 23-39.

Mah SP, Saueressig H, Goulding M, Kintner C, Dressler GR. 2000. Kidney development in cadherin-6 mutants: Delayed mesenchyme-to-epithelial conversion and loss of nephrons. Dev Biol 223: 38-53.

Manie S, Santoro M, Fusco A, Billaud M. 2001. The RET receptor: Function in development and dysfunction in congenital malformation. Trends Genet 17: 580-589.

Marlier A, Schmidt-Ott KM, Gallagher AR, Barasch J, Karihaloo A. 2009. VEGF as an epithelial cell morphogen modulates branching moprhogenesis of embryonic kidney by directly acting on the ureteric bud. Mech Dev 126: 91-98.

Marose TD, Merkel CE, McMahon AP, Carroll TJ. 2008. $\beta$-catenin is necessary to keep cells of ureteric bud/Wolffian duct epithelium in a precursor state. Dev Biol 314: 112-126.

Martínez-Estrada OM, Lettice LA, Essafi A, Guadix JA, Slight J, Velecela V, Hall E, Reichmann J, Devenney PS, Hohenstein P, et al. 2010. Wt1 is required for cardiovascular progenitor cell formation through transcriptional control of Snail and E-cadherin. Nat Genet 42: 89-93.

McMahon AP, Aronow BJ, Davidson DR, Davies JA, Gaido KW, Grimmond S, Lessard JL, Little MH, Potter SS, Wilder EL, et al. 2008. GUDMAP: The genitourinary developmental molecular anatomy project. $J$ Am Soc Nephrol 19: 667-671.

Metzger RJ, Klein OD, Martin GR, Krasnow MA. 2008. The branching programme of mouse lung development. Nature 453: 745-750.

Michos O, Gonçalves A, Lopez-Rios J, Tiecke E, Naillat F, Beier K, Galli A, Vainio S, Zeller R. 2007. Reduction of BMP4 activity by gremlin 1 enables ureteric bud outgrowth and GDNF/WNT11 feedback signalling during kidney branching morphogenesis. Development 134: $2397-$ 2405.

Michos O, Cebrian C, Hyink D, Grieshammer U, Williams L, D'Agati V, Licht JD, Martin GR, Costantini F. 2010. Kidney development in the absence of Gdnf and Spry1 requires Fgf10. PLoS Genet 6: e1000809.

Miner JH. 2005. Building the glomerulus: A matricentric view. J Am Soc Nephrol 16: 857-861.

Miyazaki Y, Oshima K, Fogo A, Ichikawa I. 2003. Evidence that bone morphogenetic protein 4 has multiple biological functions during kidney and urinary tract development. Kidney Int 63: 835-844.

Mudumana SP, Hentschel D, Liu Y, Vasilyev A, Drummond IA. 2008. Odd skipped related 1 reveals a novel role for endoderm in regulating kidney versus vascular cell fate. Development 135: 3355-3367.

Mugford JW, Sipila P, McMahon JA, McMahon AP. 2008a. Osr1 expression demarcates a multi-potent population of intermediate mesoderm that undergoes progressive restriction to an Osr1-dependent nephron progenigor compartment within the mammalian kidney. Dev Biol 324: 88-98.

Mugford JW, Sipila P, Kobayashi A, Behringer RR, McMahon AP. 2008b. Hoxd11 specifies a program of metanephric kidney development within the intermediate mesoderm of the mouse embryo. Dev Biol 319: 396-405.

Mugford JW, Yu J, Kobayashi A, McMahon AP. 2009. High-resolution gene expression analysis of the developing mouse kidney defines novel cellular compartments within the nephron progenitor population. Dev Biol 333: 312-323. 
Müller RU, Zank S, Fabretti F, Benzing T. 2011. Caenorhabditis elegans, a model organism for kidney research: From cilia to mechanosensation and longevity. Curr Opin Nephrol Hypertens 20: 400-408.

Nakai S, Sugitani Y, Sato H, Ito S, Miura Y, Ogawa M, Nishi M, Jishage K, Minowa O, Noda T. 2003. Crucial roles of Brn1 in distal tubule formation and function in mouse kidney. Development 130: 47514759.

Nakano T, Niimura F, Hohenfellner K, Miyakita E, Ichikawa I. 2003. Screening for mutations in BMP4 and FOXC1 genes in congenital anomalies of the kidney and urinary tract in humans. Tokai J Exp Clin Med 28: 121-126.

Oxburgh L, Chu GC, Michael SK, Robertson EJ. 2004. TGFß superfamily signals are required for morphogenesis of the kidney mesenchyme progenitor population. Development 131: 4593-4605.

Oxburgh L, Brown AC, Fetting J, Hill B. 2011. BMP signaling in the nephron progenitor niche. Pediatr Nephrol 26: 1491-1497.

Pallister PD, Hecht F, Herrman J. 1989. Three additional cases of the congenital hypothalamic "hamartoblastoma" (Pallister-Hall) syndrome. Am J Med Genet 33: 500-501.

Park JS, Valerius MT, McMahon AP. 2007. Wnt/ $\beta$-catenin signaling regulates nephron induction during mouse kidney development. Development 134: 2533-2539.

Patel SR, Kim D, Levitan I, Dressler GR. 2007. The BRCT-domain containing protein PTIP links PAX2 to a histone H3, lysine 4 methyltransferase complex. Dev Cell 13: 580-592.

Pedersen A, Skjong C, Shawlot W. 2005. Lim 1 is required for nephric duct extension and ureteric bud morphogenesis. Dev Biol 288: 571581.

Pepicelli CV, Kispert A, Rowitch DH, McMahon AP. 1997. GDNF induces branching and increased cell proliferation in the ureter of the mouse. Dev Biol 192: 193-198.

Perälä N, Jakobson M, Ola R, Fazzari P, Penachioni JY, Nymark M, Tanninen T, Immonen T, Tamagnone L, Sariola H. 2011. Sema4C-Plexin B2 signalling modulates ureteric branching in developing kidney. Differentiation 81: 81-91.

Perantoni AO, Timofeeva O, Naillat F, Richman C, Pajni-Underwood S, Wilson C, Vainio S, Dove LF, Lewandoski M. 2005. Inactivation of FGF8 in early mesoderm reveals an essential role in kidney development. Development 132: 3859-3871.

Pini Prato A, Musso M, Ceccherini I, Mattioli G, Giunta C, Ghiggeri GM, Jasonni V. 2009. Hirschsprung disease and congenital anomalies of the kidney and urinary tract (CAKUT): A novel syndromic association. Medicine 88: 83-90.

Poladia DP, Kish K, Kutay B, Hains D, Kegg H, Zhao H, Bates CM. 2006. Role of fibroblast growth factor receptors 1 and 2 in the metanephric mesenchyme. Dev Biol 291: 325-339.

Quaggin SE, Kreidberg JA. 2008. Development of the renal glomerulus: Good neighbors and good fences. Development 135: 609-620.

Raatikainen-Ahokas A, Hytönen M, Tenhunen A, Sainio K, Sariola H. 2000. BMP-4 affects the differentiation of metanephric mesenchyme and reveals an early anterior-posterior axis of the embryonic kidney. Dev Dyn 217: 146-158.

Reginensi A, Clarkson M, Neirijnck Y, Lu B, Ohyama T, Groves AK, Sock E, Wegner M, Costantini F, Chaboissier MC, et al. 2011. SOX9 controls epithelial branching by activating RETeffector genes during kidney development. Hum Mol Genet 20: 1143-1153.

Robert B, St John PL, Abrahamson DR. 1998. Direct visualization of renal vascular morphogenesis in Flk1 heterozygous mutant mice. Am J Physiol 275: F164-F172.

Ronconi E, Sagrinati C, Angelotti ML, Lazzeri E, Mazzinghi B, Ballerini L, Parente E, Becherucci F, Gacci M, Carini M, et al. 2009. Regeneration of glomerular podocytes by human renal progenitors. J Am Soc Nephrol 20: $322-332$.

Rosselot C, Spraggon L, Chia I, Batourina E, Riccio P, Lu B, Niederreither K, Dolle P, Duester G, Chambon P, et al. 2010. Non-cell-autonomous retinoid signaling is crucial for renal development. Development 137: $283-292$.
Rumballe B, Georgas KM, Combes AN, Ju AL, Gilbert T, Little MH. 2011. Nephron formation adopts a novel spatial topology at cessation of nephrogenesis. Dev Biol doi: 10.1016/j.ydbio.2011.09.011.

Sajithlal G, Zou D, Silvius D, Xu PX. 2005. Eya 1 acts as a critical regulator for specifying the metanephric mesenchyme. Dev Biol 284: 323-336.

Sato A, Matsumoto Y, Koide U, Kataoka Y, Yoshida N, Yokota T, Asashima M, Nishinakamura R. 2003. Zinc finger protein sall2 is not essential for embryonic and kidney development. Mol Cell Biol 23: 62-69.

Saxén L. 1987. Organogenesis of the kidney. Cambridge University Press, Cambridge.

Self M, Lagutin OV, Bowling B, Hendrix J, Cai Y, Dressler GR, Oliver G. 2006. Six2 is required for suppression of nephrogenesis and progenitor renewal in the developing kidney. EMBO J 25: 5214-5228.

Seow HF, Bröer S, Bröer A, Bailey CG, Potter SJ, Cavanaugh JA, Rasko JE. 2004. Hartnup disorder is caused by mutations in the gene encoding the neutral amino acid transporter SLC6A19. Nat Genet 36: 10031007.

Shi S, Yu L, Chiu C, Sun Y, Chen J, Khitrov G, Merkenschlager M, Holzman LB, Zhang W, Mundel P, et al. 2008. Podocyte-selective deletion of dicer induces proteinuria and glomerulosclerosis. J Am Soc Nephrol 19: 2159-2169.

Sim EU, Smith A, Szilagi E, Rae F, Ioannou P, Lindsay MH, Little MH. 2002. Wnt- 4 regulation by the Wilms' tumour suppressor gene, WT1. Oncogene 21: 2948-2960.

Simons M, Hartleben B, Huber TB. 2009. Podocyte polarity signalling. Curr Opin Nephrol Hypertens 18: 324-330.

Song R, Yosypiv IV. 2011. Genetics of congenital anomalies of the kidney and urinary tract. Pediatr Nephrol 26: 353-364.

Song R, Spera M, Garrett C, Yosypiv IV. 2010. Angiotensin II-induced activation of c-Ret signaling is critical in ureteric bud branching morphogenesis. Mech Dev 127: 21-27.

Tabatabaeifar M, Schlingmann KP, Litwin M, Emre S, Bakkaloglu A, Mehls O, Antignac C, Schaefer F, Weber S, ESCAPE Trial Group. 2009. Functional analysis of BMP4 mutations identified in pediatric CAKUT patients. Pediatr Nephrol 24: 2361-2368.

Takeda S, Rogers SA, Hammerman MR. 2006. Differential origin for endothelial and mesangial cells after transplantation of pig fetal renal primordia into rats. Transpl Immunol 15: 211-215.

Takemoto M, He L, Norlin J, Patrakka J, Xiao Z, Petrova T, Bondjers C, Asp J, Wallgard E, Sun Y, et al. 2006. Large-scale identification of genes implicated in kidney glomerulus development and function. EMBO J 25: $1160-1174$.

Tanigawa S, Wang H, Yang Y, Sharma N, Tarasova N, Ajima R, Yamaguchi TP, Rodriguez LG, Perantoni AO. 2011. Wnt4 induces nephronic tubules in metanephric mesenchyme by a non-canonical mechanism. Dev Biol 352: 58-69.

Thiagarajan RD, Georgas KM, Rumballe BA, Lesieur E, Chiu HS, Taylor D, Tang DT, Grimmond SM, Little MH. 2011. Identification of anchor genes during kidney development defines ontological relationships, molecular subcompartments and regulatory pathways. PLoS One 6: e17286.

Torres M, Gomez-Pardo E, Dressler GR, Gruss P. 1995. Pax-2 controls multiple steps of urogenital development. Development 121: 40574065.

Tsang TE, Shawlot W, Kinder SJ, Kobayashi A, Kwan KM, Schughart K, Kania A, Jessell TM, Behringer RR, Tam PP. 2000. Lim1 activity is required for intermediate mesoderm differentiation in the mouse embryo. Dev Biol 223: 77-90.

Tufro A, Teichman J, Banu N, Villegas G. 2007. Crosstalk between VEGF-A/VEGFR2 and GDNF/RET signaling pathways. Biochem Biophys Res Commun 358: 410-416.

Tufro A, Teichman J, Woda C, Villegas G. 2008. Semaphorin3a inhibits ureteric bud branching morphogenesis. Mech Dev 125: 558-568.

Ueda H, Miyazaki Y, Matsusaka T, Utsunomiya Y, Kawamura T, Hosoya T, Ichikawa I. 2008. Bmp in podocytes is essential for normal glomerular capillary formation. J Am Soc Nephrol 19: 685-694. 
Vajjhala PR, Macmillan E, Gonda T, Little M. 2003. The Wilms' tumour suppressor protein, WT1, undergoes CRM1-independent nucleocytoplasmic shuttling. FEBS Lett 554: 143-148.

Vanslambrouck JM, Bröer A, Thavyogarajah T, Holst J, Bailey CG, Bröer S, Rasko JE. 2010. Renal imino acid and glycine transport system ontogeny and involvement in developmental iminoglycinuria. Biochem $J$ 428: 397-407.

Villanueva S, Céspedes C, Vio CP. 2006. Ischemic acute renal failure induces the expression of a wide range of nephrogenic proteins. Am J Physiol Regul Integr Comp Physiol 290: R861-R870.

Vogetseder A, Palan T, Bacic D, Kaissling B, Le Hir M. 2007. Proximal tubular epithelial cells are generated by division of differentiated cells in the healthy kidney. Am J Physiol Cell Physiol 294: C22C28.

Wellik DM, Hawkes PJ, Capecchi MR. 2002. Hox11 paralogous genes are essential for metanephric kidney induction. Genes Dev 16: 14231432.

Wells J, Rivera MN, Kim WJ, Starbuck K, Haber DA. 2010. The predominant WT1 isoform (+KTS) encodes a DNA-binding protein targeting the planar cell polarity gene Scribble in renal podocytes. Mol Cancer Res 8: 975-985.

Winyard P, Chitty LS. 2008. Dysplastic kidneys. Semin Fetal Neonatal Med 13: $142-151$.

Wong A, Bogni S, Kokta P, de Graaff E, D’Agati V, Costantini F, Pachnis V. 2005. Phosphotyrosine 1062 is critical for the in vivo activity of the Ret9 receptor tyrosone kinase isoform. Mol Cell Biol 25: 96619673.

Xu PX, Zheng W, Huang L, Maire P, Laclef C, Silvius D. 2003. Six1 is required for the early organogenesis of mammalian kidney. Development 130: 3085-3094.

Ye X, Wang Y, Rattner A, Nathans J. 2011. Genetic mosaic analysis reveals a major role for frizzled 4 and frizzled 8 in controlling ureteric growth in the developing kidney. Development 138: 1161-1172.

Yosypiv IV, Schroeder M, El-Dahr SS. 2006. Angiotensin II type 1 receptor-EGF receptor cross-talk regulates ureteric bud branching morphogenesis. J Am Soc Nephrol 17: 1005-1014.

Yu J, Carroll TJ, McMahon AP. 2002. Sonic hedgehog regulates proliferation and differentiation of mesenchymal cells in the mouse metanephric kidney. Development 129: 5301-5312.

Yu J, Carroll TJ, Rajagopal J, Kobayashi A, Ren Q, McMahon AP. 2009. A Wnt7b-dependent pathway regulates the orientation of epithelial cell division and establishes the cortico-medullary axis of the mammalian kidney. Development 136: 161-171.

Zeisberg EM, Potenta SE, Sugimoto H, Zeisberg M, Kalluri R. 2008. Fibroblasts in kidney fibrosis emerge via endothelial-to-mesenchymal transition. J Am Soc Nephrol 19: 2282-2287.

Zhdanova O, Srivastava S, Di L, Li Z, Tchelebi L, Dworkin S, Johnstone DB, Zavadil J, Chong MM, Littman DR, et al. 2011. The inducible deletion of Drosha and microRNAs in mature podocytes results in a collapsing glomerulopathy. Kidney Int 80: 719-730. 


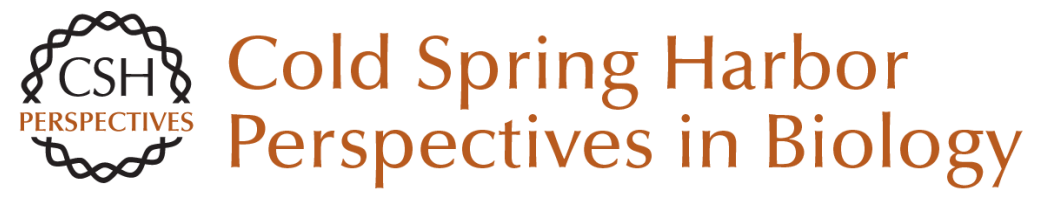

\section{Mammalian Kidney Development: Principles, Progress, and Projections}

Melissa H. Little and Andrew P. McMahon

Cold Spring Harb Perspect Biol 2012; doi: 10.1101/cshperspect.a008300

Subject Collection Mammalian Development

The Dynamics of Morphogenesis in the Early Mouse Embryo

Jaime A. Rivera-Pérez and Anna-Katerina Hadjantonakis

microRNAs as Developmental Regulators Kathryn N. Ivey and Deepak Srivastava

Development of the Endochondral Skeleton Fanxin Long and David M. Ornitz

Adipogenesis Kelesha Sarjeant and Jacqueline M. Stephens

Molecular Mechanisms of Inner Ear Development Doris K. Wu and Matthew W. Kelley

Polarity in Mammalian Epithelial Morphogenesis Julie Roignot, Xiao Peng and Keith Mostov

Eye Development and Retinogenesis Whitney Heavner and Larysa Pevny

Primordial Germ Cells in Mice Mitinori Saitou and Masashi Yamaji
Cell Division Modes and Cleavage Planes of Neural Progenitors during Mammalian Cortical Development

Fumio Matsuzaki and Atsunori Shitamukai

Blood and Lymphatic Vessel Formation Victoria L. Bautch and Kathleen M. Caron

Transcriptional Networks in Liver and Intestinal

Development Karyn L. Sheaffer and Klaus H. Kaestner

Pluripotency in the Embryo and in Culture Jennifer Nichols and Austin Smith

Signaling and Transcriptional Networks in Heart Development and Regeneration Benoit G. Bruneau

Signals and Switches in Mammalian Neural Crest Cell Differentiation Shachi Bhatt, Raul Diaz and Paul A. Trainor

Hematopoiesis Michael A. Rieger and Timm Schroeder

Intercellular Interactions, Position, and Polarity in Establishing Blastocyst Cell Lineages and

Embryonic Axes

Robert O. Stephenson, Janet Rossant and Patrick P.L. Tam

For additional articles in this collection, see http://cshperspectives.cshlp.org/cgi/collection/

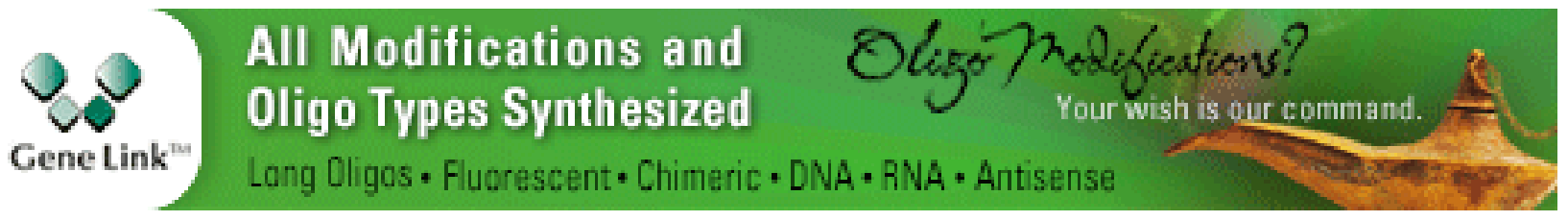

Copyright (C 2012 Cold Spring Harbor Laboratory Press; all rights reserved 